Exportação de carga poluidora para identificação de áreas úmidas sob risco ambiental na bacia hidrográfica da lagoa mirim Valdir Adilson Steinke, Carlos Hiroo Saito

\title{
EXPORTAÇÃO DE CARGA POLUIDORA PARA IDENTIFICAÇÃO DE ÁREAS ÚMIDAS SOB RISCO AMBIENTAL NA BACIA HIDROGRÁFICA DA LAGOA MIRIM
}

\section{Polluting load exportation for identification of humid areas under environmental risk in the river basin of Lagoa Mirim}

Valdir Adilson Steinke

Dr. em Ecologia - UNB, Professor do Departamento de Geografia do Centro Universitário de Brasília - UniCEUB.

valdirsteinke@gmail.com

Carlos Hiroo Saito

Dr. em Geografia, Professor Adjunto do Departamento de Ecologia da Universidade de Brasília.

saito@unb.br

Artigo recebido para publicação em 06/11/07 e aceito para publicação em 04/05/08

RESUMO: $\quad$ Para compreender bacias hidrográficas, é necessário que todos os elementos da paisagem sejam analisados de maneira transversal, no tempo e no espaço. Esse trabalho teve como objetivo analisar a bacia de contribuição direta da Lagoa Mirim por meio dos tipos de uso da terra e seus impactos nas áreas úmidas nela situadas. Utilizando um Sistema de Informações Geográficas, foram calculados, por meio de dois modelos, o MQUAL e o PLOAD, parâmetros de carga poluidora e identificadas áreas mais ameaçadas por poluição, a partir do tipo de uso da terra. As análises revelaram a necessidade de uma gestão compartilhada da bacia.

Palavras-chave: Bacia Transfronteiriça, Geoprocessamento, Lagoa Mirim.

ABSTRACT: To understand the river basin, it is necessary to analyze all elements of the landscape in a transversal way, in time and space. The objective of this work was to analyze the basin of direct contribution of the Lagoa Mirim by the types of the land use and its impacts in the wetlands of the basin. Using a Geographic Information System, load polluting parameters were calculated by two models, the MQUAL and the PLOAD, identifying the most threatened areas by pollution. The analyzes revealed the necessity of a shared management of the basin.

Keywords: GIS, Cross border river basins, Lagoa Mirim.

\section{INTRODUÇÃO}

Os diferentes métodos que a sociedade moderna adotou para exploração do planeta Terra passam, na atualidade, por discussões conceituais na expectativa de reorganizar as atividades produtivas, desde a busca de novas concepções culturais até as tentativas imediatas de equacionar problemas pontuais. Entre alguns exemplos, pode-se citar a preocupação com a preservação dos recursos naturais, com a inserção do conceito de sustentabilidade, enraizado na maioria das decisões políticas dos 
governos, e que responde a inúmeros setores da sociedade civil.

Esta revisão conceitual passa necessariamente pela reformulação de idéias, ou seja, rever como o processo de uso e ocupação da terra está ocorrendo e buscar alternativas para minimizar os impactos negativos das atividades antrópicas sobre os demais elementos que compõem a paisagem, com a proposição de medidas mitigadoras.

Entre essas medidas, encontram-se os Planos de Recuperação de Áreas Degradadas, destinados às áreas que já se encontram deterioradas; os Planos de Manejo, que podem atender áreas públicas como as Unidades de Conservação; as áreas de produção agrícola, pastoril, silvicultura, entre outras; os Planos Diretores Municipais e as propostas de Zoneamento Ecológico-Econômico.

Os documentos citados têm mostrado que a relação entre os tipos de uso da terra e seus reflexos é maior do que se pensava. Para o continente Europeu, Vighi \& Chiaudani (1987) mostraram que os índices de fósforo que são transferidos para os corpos d'água chegam a 70\%, enquanto que Gburek \& Sharpley (1998) apontaram que, nos Estados Unidos, mais de $50 \%$ dos contaminantes de um corpo d'água são provenientes da atividade agrícola. Para o Brasil, as estimativas são pessimistas, pois o aumento na produção agropecuária na última década foi de aproximadamente $33 \%$. Por uma associação direta, este dado remete a um aumento da mesma ordem na transferência de químicos para os corpos d'água (SHIGAKI et al. 2006).

Devido aos grandes problemas de sedimentação, eutrofização e degradação ambiental dos sistemas aquáticos, envolvendo cursos d'água, lagos e reservatórios, a identificação e classificação das áreas fornecedoras de substâncias como a matéria orgânica, o Nitrogênio e o Fósforo, que contribuem para o aparecimento de tais problemas, é de grande importância no planejamento e na adoção de medidas de controle da poluição difusa, principalmente por atividades agrícolas devido a extensão territorial das áreas utilizadas para tal fim.

Conhecer os efeitos dos diferentes tipos de uso da terra sobre o escoamento superficial em uma bacia hidrográfica é fundamental para o manejo e tomada de decisões dos diferentes usuários da bacia. Kuhnle (1996) ressaltou que conhecer o processo de movimento dos sedimentos é extremamente importante para o manejo do uso da terra em bacias hidrográficas.

$\mathrm{Na}$ medida em que as cargas poluidoras pontuais são identificadas e controladas de maneira mais eficaz, os estudos passam a ser dirigidos para a questão do escoamento superficial, ou seja, a poluição não pontual, ou difusa, elevando a preocupação com os aspectos de transporte de sedimentos e nutrientes em suspensão (CARPENTER et al. 1998; TANIK et. al. 1999; WITT \& BEHRENDT, 1999; MACLEOD \& HAYGARTH, 2003; SILVA \& PORTO, 2003; MACHADO \& VETTORAZZI, 2003; MACHADO et. al. 2003; MANSOR et al. 2006, SHIGAKI et. al. 2006).

Uma das opções de modelagem ambiental, incluindo a identificação de áreas com maior exportação de carga poluidora e as áreas mais susceptíveis ao recebimento destas cargas, constituise na elaboração de planos de informação georreferenciados, os quais podem ser sobrepostos e processados em ambiente de geoprocessamento.

O geoprocessamento representa, na atualidade, um importante subsídio às pesquisas que envolvem a modelagem de sistemas ambientais, pois lidam com a complexidade da dinâmica ambiental, uma vez que, por meio da localização e do processamento de dados geográficos, é capaz de ser o aglutinador das diferentes áreas do conhecimento, o que proporciona uma abordagem sistêmica da paisagem. A definição do termo "geoprocessamento" ainda é objeto de discussão entre aqueles que se dedicam a esta área, o que acabou gerando uma gama de terminologias que são utilizadas por diferentes grupos de pesquisa no Brasil e no mundo. Os seguintes autores são as principais referências ao tema:

Sociedade \& Natureza, Uberlândia, 20 (2): 43-67, DEZ. 2008 
Burrough (1986 \& 1998); Rodrigues (1993); Xavier da Silva (1993 \& 1999); Aranoff (1995); Calijuri \& Röhm (1995); Assad e Sano (1998); Câmara \& Medeiros (1998); Xavier da Silva (2000) apud Rocha (2000); Rocha (2000); Davis (2001); Miranda (2005).

Com a finalidade de comparar sistemas produtivos ecológicos e não ecológicos, Giupponi et. al. (1999) utilizaram análise multicritério e um sistema de informação geográfica para produzir mapas de risco de poluição por atividades agrícolas na bacia da Lagoa Venice - Itália. Foram gerados e avaliados diferentes cenários em termos de risco de poluição dos recursos hídricos, levando-se em consideração a vulnerabilidade local. Os resultados demonstraram um grande potencial das práticas ecológicas para redução dos riscos de poluição na água superficial e subterrânea.

Matejicek et. al. (2003) desenvolveram um modelo de monitoramento de poluição da água conjugando as características da bacia hidrográfica e os atributos da cobertura da terra, com o objetivo de analisar a variação espaço-temporal de nitrato $\left(\mathrm{NO}_{3}\right)$ em uma pequena bacia da Bohemia - República Tcheca. Os parâmetros do modelo foram estimados por meio de dados experimentais de qualidade da água juntamente com os tipos de cobertura que servem de armazenamento ou transformadores dos nutrientes. O estudo permitiu a elaboração de uma metodologia para determinar as áreas potenciais de poluição por nitrato oriundo de fontes pontuais e não pontuais utilizando técnicas de sensoriamento remoto. Os autores mostraram que a metodologia pode auxiliar os processos de tomada de decisão, visando melhores práticas de manejo nas bacias.

Yuan et. al. (2007) desenvolveram um sistema integrado de modelagem para o monitoramento da qualidade da água em bacias costeiras. Foram incluídos no sistema, um modelo ligando as entradas da poluição com o uso da terra e um modelo para simular o fluxo superficial e os processos químicos e biológicos. Baseado em indicadores sociais e econômicos tais como população e produção industrial e indicadores ambientais como volume de água, tipo de poluente e quantidade de chuva, um estudo detalhado de modelagem foi aplicado para estimar a poluição difusa e pontual na bacia de Bohai na China. O trabalho demonstrou, mais uma vez, a aplicabilidade da ferramenta GIS como sendo muito útil para os gestores ambientais e para o governo local no planejamento e gestão da qualidade da água.

Lopes et al. (2007), aplicando técnicas de geoprocessamento, identificaram as áreas com potencial fornecimento de fósforo para os corpos d'água utilizando a metodologia P-Index, com a finalidade de fornecer subsídios a gestão de mananciais de uma bacia hidrográfica. Os autores observaram que a intensidade no uso da terra associada às práticas não conservacionistas constituem os fatores que mais contribuem para o risco de contaminação.

Vários outros trabalhos têm sido desenvolvidos na mesma linha: Schou et al. (2000), na bacia do rio Vejle Fjord na Dinamarca; Sivertun e Prange (2003), para a bacia do rio Gisselö na Suécia; Mohamed et al. (2004), para a bacia do rio Kori Etiópia; Mufano et al. (2005), para a bacia do rio Tiber na Itália; Geneletti (2006), para a bacia do rio Avisio na Itália; Lepistö (2006), para 30 bacias de contribuição dos estuários na Finlândia; Paliwal et al. (2007) para a bacia do rio Yamuna - Índia; Xiao e Ji (2007), para a uma bacia compartilhada pelos Estados de Missouri, Oklaoma e Kansas nos EUA.

A Lagoa Mirim constitui-se em uma das mais importantes lagoas de água doce do território brasileiro e da América do Sul. Com aproximadamente 375 mil hectares de superfície de água, é o segundo maior corpo hídrico com características lacustres do Brasil, sendo superada apenas pela Laguna dos Patos, também no Brasil (Kotzian \& Marques, 2004). Representa valiosa fonte de recursos pesqueiros para um grande número de famílias que vivem da pesca artesanal e que vêm sofrendo uma forte pressão antrópica em função das atividades agropastoris desenvolvidas em seu entorno, tanto em território brasileiro quanto no uruguaio, por meio de extensas lavouras de arroz irrigado. Esse 
aspecto também torna a região importante do ponto de vista econômico, pois a atividade arrozeira impulsiona o desenvolvimento econômico da região. Além disso, apresenta, em seu entorno, áreas úmidas de grande importância para o ecossistema como um todo.

As áreas úmidas são zonas resultantes de dois fatores correlacionados, a geomorfologia e os recursos hídricos de um determinado ambiente. O relevo apresenta características que favorecem o acúmulo de água que, por sua vez, controla a vida animal e vegetal deste ambiente.

As zonas úmidas estão entre os ecossistemas de maior produtividade do planeta e, por isso, beneficiam de modo importante os aspectos sociais e econômicos da população, principalmente pela disponibilidade de água doce. Isso requer um manejo adequado destes ambientes.

Os ambientes úmidos oferecem alguns benefícios importantes através de seus recursos, funções e atributos. Como recursos, podem ser citados a água, os peixes, as madeiras, as fibras, os crustáceos, as plantas medicinais e todo o conjunto de vida silvestre. Apresentam as seguintes funções: provisão de água doce, regulação de inundações e secas, retenção de sedimentos e nutrientes, remoção de tóxicos, estabilização de microclimas, retenção de carbono, turismo, recarga de aqüíferos, entre outros, e, como atributos, pode-se elencar, principalmente, o banco genético e a importância sócio-ambiental. Desta forma, o uso com base em planejamento sustentável desses ambientes pode proporcionar significativos benefícios às populações locais e à economia regional.

No dia 02 de fevereiro de 1971, na cidade de Ramsar, no Irã, foi aprovado e assinado o tratado intergovernamental sobre áreas úmidas, a Convenção sobre umidades de importância internacional, ou como se convencionou denominar de Convenção Ramsar.

Os países que aderiram à convenção assumem a responsabilidade de estabelecer sítios Ramsar em seu território, somando esforços, a nível internacional, pela preservação dos ambientes úmidos. O Brasil atualmente conta com oito sítios já designados e outros estão em fase de estudo para serem designados como de importância internacional.

A missão da convenção de Ramsar consiste na conservação e uso racional de todas as áreas úmidas, mediante ações locais, regionais e nacionais com a cooperação internacional, visando o desenvolvimento sustentável a nível mundial. Sendo as áreas úmidas o foco da convenção Ramsar, esta define áreas úmidas como:

Toda extensão de pântanos, charcos e turfas, ou superfícies cobertas de água, de regime natural ou artificial, permanentes ou temporárias, com água parada ou corrente, doce, salobra ou salgada. As áreas marinhas também são consideradas zonas úmidas, contanto que a profundidade da maré baixa não exceda a seis metros. Também foi estabelecido que essas Zonas Úmidas podem compreender as regiões ribeirinhas ou costeiras adjacentes, assim como as ilhas ou extensões de áreas marinhas de uma profundidade superior aos seis metros em maré baixa. Como resultado destas determinações, a cobertura da Convenção se estende a uma ampla variedade de ecossistemas aquáticos, incluindo rios, zonas costeiras/marinhas e zonas úmidas artificiais, tais como lagoas, açudes e represas. (MMA, 2007)

Neste contexto, o presente trabalho teve, como objetivo principal, identificar as áreas úmidas sob risco de contaminação em função do tipo de uso da terra na bacia de contribuição direta da Lagoa Mirim, com vistas à gestão compartilhada de bacias hidrográficas transfronteiriças.

\section{MATERIAIS E MÉTODOS}

\section{Área de Estudo}

A Bacia Hidrográfica da Lagoa Mirim, além dos aspectos relacionados à biodiversidade aquática, apresenta-se como um importante cenário histórico, no que diz respeito à delimitação da fronteira

Sociedade \& Natureza, Uberlândia, 20 (2): 43-67, DEZ. 2008 
internacional com o Uruguai. Essa fronteira já passou por inúmeras alterações ao longo do processo histórico de construção dos limites territoriais, os quais seguem os mais diferentes aspectos, e esses relacionados a motivos diversos, sendo que, em boa parte, as fronteiras estão estabelecidas por aspectos físicos, principalmente, o curso d'água.

Um dos primeiros mapas gerados para o estabelecimento da fronteira entre o Brasil e o Uruguai, o qual se refere à Província de São Pedro do Rio Grande do Sul do visconde de São Leopoldo, foi confeccionado pelo Geógrafo TH-Duvotenay, em 1841. Apresentava, como limites da Província, as cabeceiras de drenagem, ou seja, o divisor de águas da bacia da Lagoa Mirim. Por este mapa, a bacia da Lagoa Mirim pertencia, em sua totalidade, ao Brasil (Figura 1).

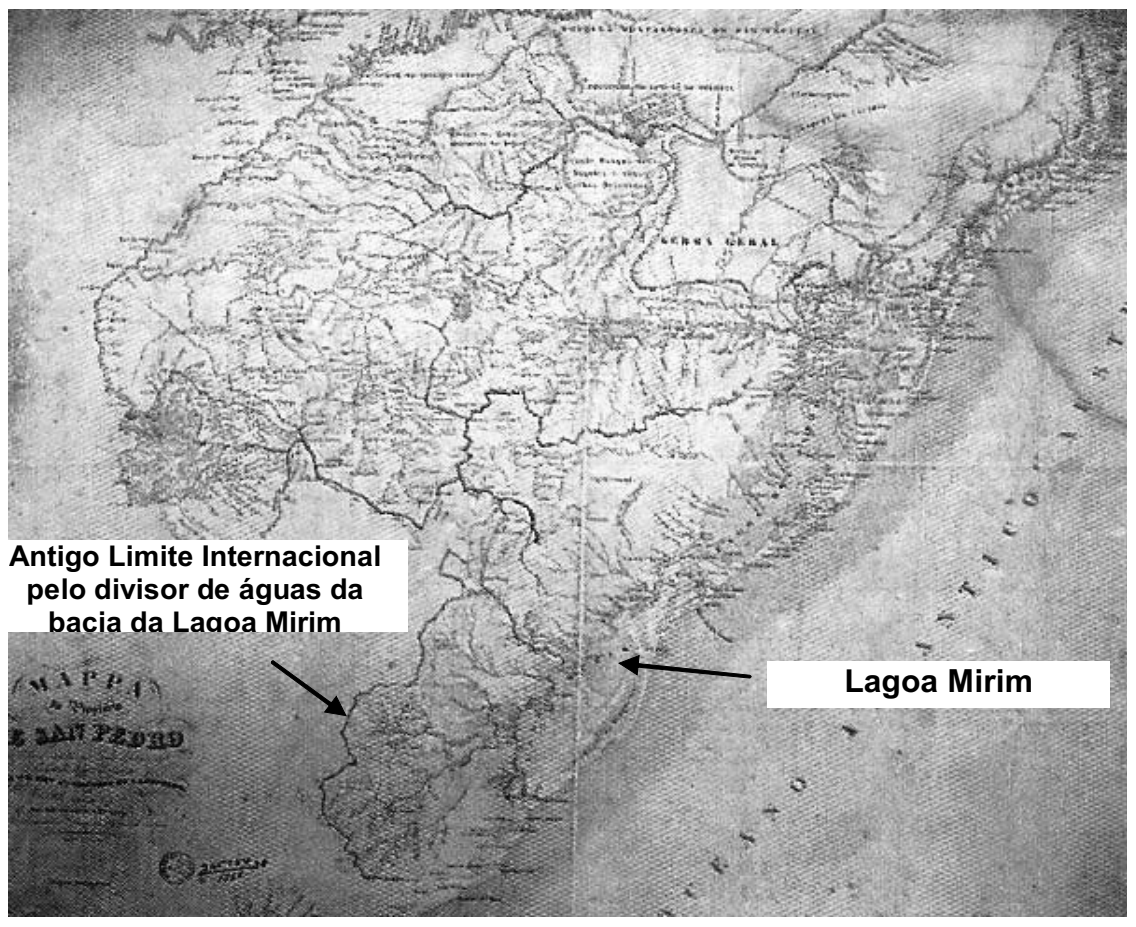

Figura 1: Limite da Fronteira pelo Divisor de Águas da Bacia Hidrográfica da Lagoa Mirim. Mapa de 1841, elaborado pelo Geógrafo TH-Duvotenay. Fonte: Biblioteca Nacional, RJ, ARC28-1-20.

Esse limite internacional passou por transformações decorrentes de conflitos históricos e adotou configurações diferentes. Em 1851, o limite estava estabelecido na margem Uruguaia da Lagoa Mirim e do Rio Jaguarão. Dessa forma, suas águas pertenciam integralmente ao Brasil. Em 1908, por determinação do Exmo. Sr. Barão do Rio Branco, na época Ministro de Estado das Relações Exteriores, um novo limite foi traçado para articular a concessão de parte de suas águas ao Uruguai, (Golin, 2002). Atualmente, a delimitação da fronteira está estabelecida pelo talvegue do rio Jaguarão até a sua foz e, a partir daí, por marcos de fronteira estabelecidos ao longo da Lagoa Mirim.

A bacia hidrográfica da Lagoa Mirim está localizada (figura 2) na costa atlântica da América do Sul, ocupa $47.362 \mathrm{~km}^{2}$ de aporte direto, e 55.110 $\mathrm{km}^{2}$ quando inclusa a faixa litorânea, na qual estão inseridos os principais banhados da região, incluindo a Lagoa Mangueira, conectada, exclusivamente, à Lagoa Mirim pelo sistema hidrológico do Taim. Na região, predomina o clima subtropical, com precipitação média anual entre 1.200 e $1.500 \mathrm{~mm}$. O 
embasamento geológico da bacia hidrográfica é composto por uma complexidade de estruturas do escudo Sul-Americano. A zona ocidental é caracterizada por uma tendência orogenética positiva que, ao final do Cenozóico, originou a formação de relevos de baixas altitudes (morros e serras), atingindo, no máximo, $520 \mathrm{~m}$. Na porção leste da bacia, os processos de intemperismo químico tiveram início no Permocarbonífero até o Jurrásico, o que permitiu um acúmulo de sedimentos na faixa de costa.
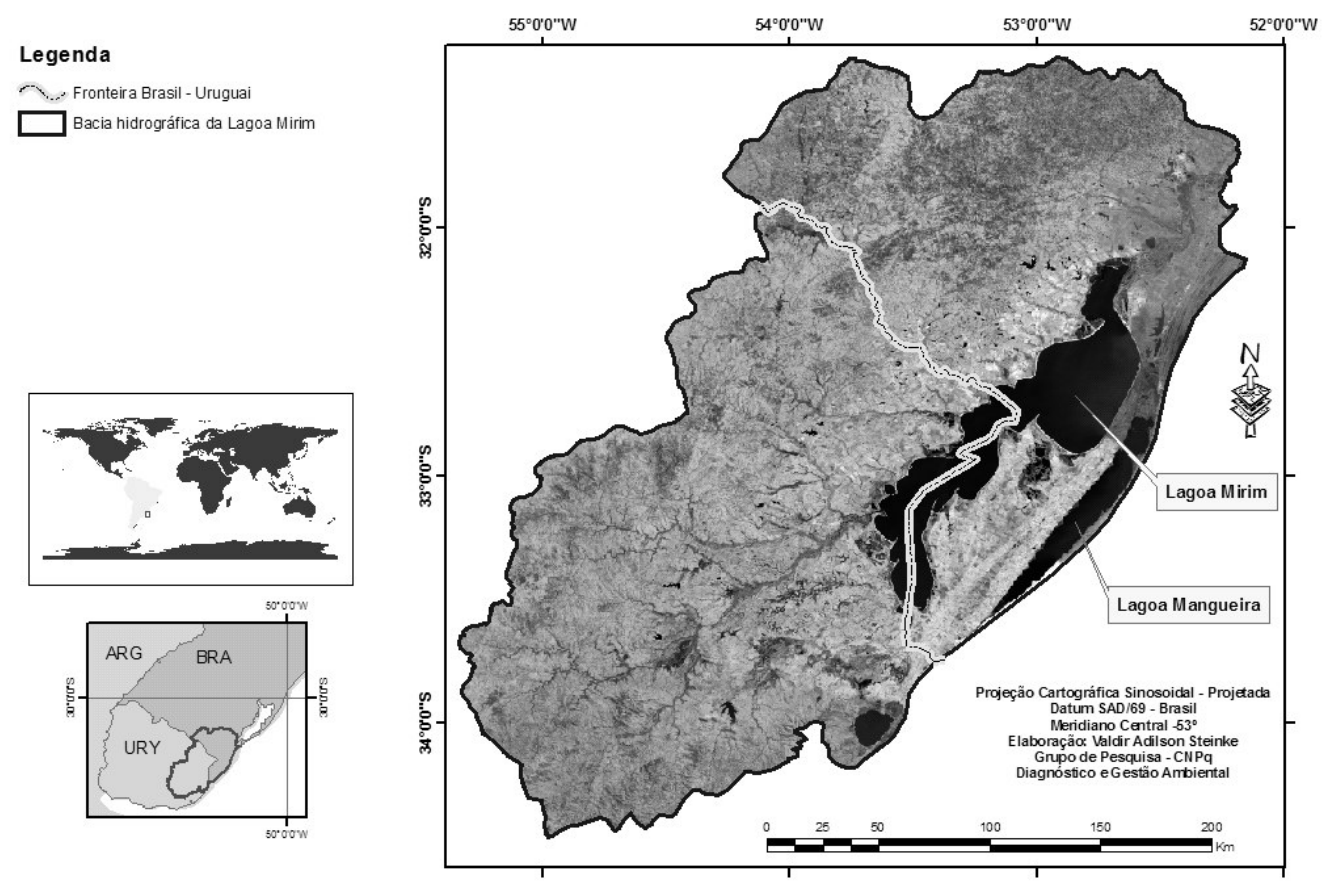

Figura 2: Mapa de localização da bacia hidrográfica da lagoa Mirim

A área de inundação da Lagoa Mirim é resultado de processos de afundamento do Jurrásico Médio e Superior que gerou a fossa tectônica da Lagoa Mirim. Durante o Cenozóico, o processo de afundamento contínuo e moderado, juntamente com os movimentos verticais lentos que ocorreram durante o Terciário e o Quaternário, originaram as baixas altitudes e os interflúvios mais elevados e extensos. A interação do desenvolvimento geológico com os elementos paleoclimáticos complexos, principalmente durante o Quaternário, resultou no relevo atual, representado pelos aplainamentos e inselbergs. A faixa de costa é resultado das transgressões marinhas, as quais deram origem à maioria dos banhados e das lagunas da costa formadas durante o Holoceno (PROBIDES, 2000; MONTAÑA \& BOSSI, 1995).
As características geomorfológicas associadas aos condicionantes climáticos, pedológicos, de disponibilidade de água e às questões sociais e culturais favoreceram a disseminação de práticas de uso da terra voltadas para a produção da pecuária de corte e a produção de arroz. Essas duas atividades dominam o sistema produtivo-econômico da região há mais de 40 anos, com destaque para o incremento da atividade arrozeira nos últimos 30 anos.

Dessa forma, a água representa valiosa fonte de recursos econômicos, tanto para o setor do agronegócio, quanto para os pescadores artesanais e tradicionais. O agronegócio predomina e suprime as demais demandas econômicas da região. Somente em território brasileiro, são plantados mais de 40.000 hectares de arroz por ano (IBGE, 2006), utilizandose da água desta bacia para irrigação. Assim, o maior 
desafio na bacia, e nas suas adjacências, constitui-se em compatibilizar o desenvolvimento social e econômico com a conservação da água e a preservação da biodiversidade.

\section{Procedimentos Metodológicos}

\section{Base de dados cartográficos}

Os procedimentos metodológicos, apresentados no fluxograma esquemático da figura 3 , ofereceram suporte à análise integrada do ambiente no contexto da bacia hidrográfica em questão. Algumas tarefas antecederam a execução dos cruzamentos das informações, as quais dizem respeito à compatibilização de uma base de dados em formato digital georreferenciado para a bacia, envolvendo os territórios do Brasil e do Uruguai.
As informações referentes à altimetria, declividade e hipsometria, em escala de 1:100.000, foram extraídas por técnica de interpolação realizada a partir da associação do mosaico de modelo digital de elevação (MDE), gerado pelo sensor Shuttle Radar Topographic Mission (SRTM/Nasa).

A essa base de informações, foram acrescentadas, em ambiente SIG, outras bases oriundas de diferentes instituições como, Probides, IBGE, MMA, FEPAM-RS, MAPA e WWF-Hydro. Essa aglutinação serviu como suporte na definição da área da bacia hidrográfica e das sub-bacias. Como as informações encontravam-se em diferentes escalas, optou-se pela padronização na escala de 1:100.000 para execução do trabalho.

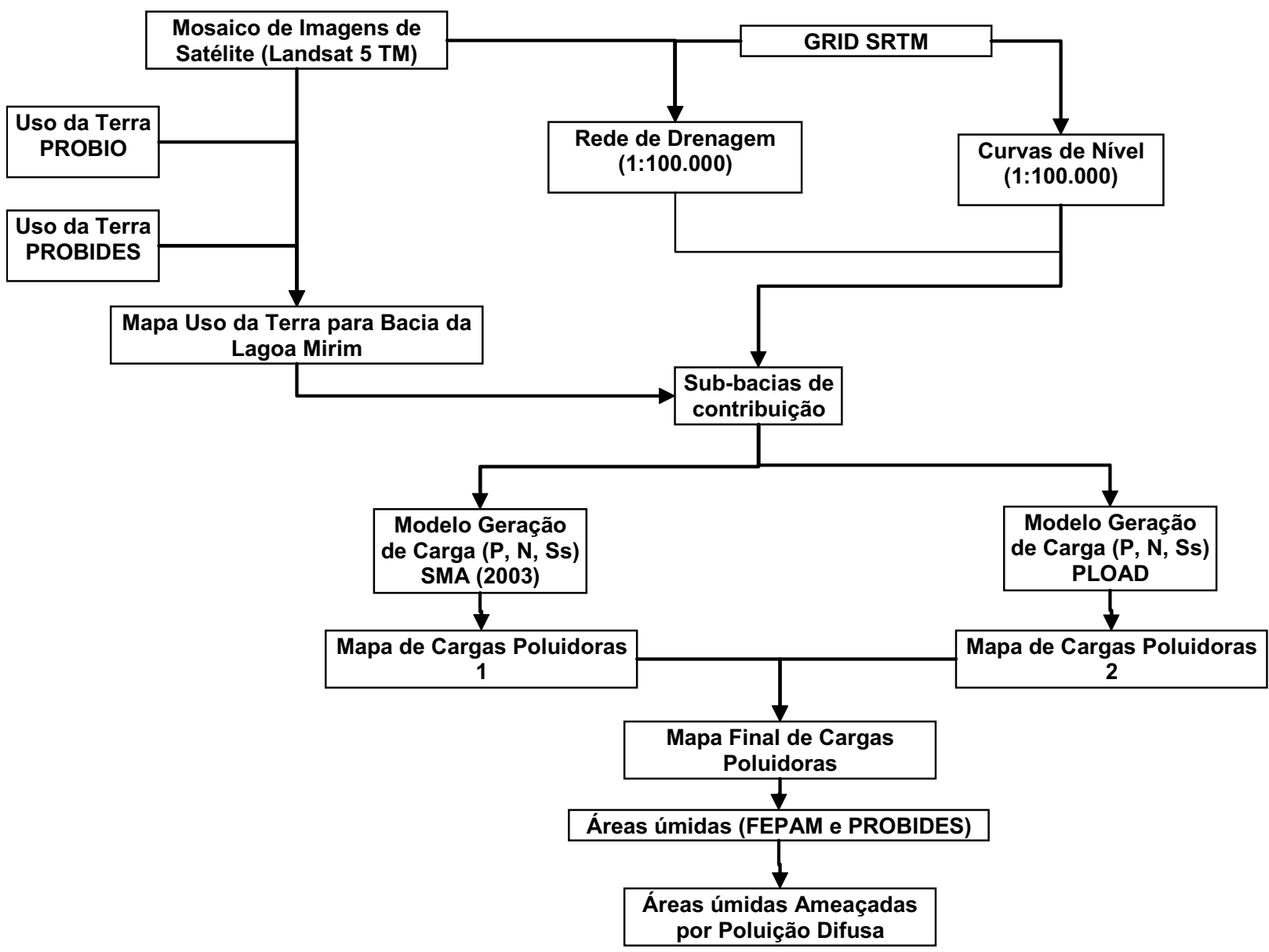

Figura 3: Fluxograma Esquemático dos Principais Procedimentos Metodológicos. 


\section{Uso da terra}

O plano de informação (PI) relativo ao uso da terra foi elaborado por meio do cruzamento de três mapas de uso da terra. O mapa elaborado pelo Probides (2000) para a porção uruguaia da bacia, o mapa elaborado pelo Probio/MMA (2006), e o mapa gerado no presente trabalho, cujo procedimento está descrito a seguir.

O mapa de uso da terra foi elaborado a partir da segmentação de imagens de satélite, com processamento digital de um mosaico de imagens LANDSAT 5 TM do ano de 2005, utilizando o método de segmentação de imagens disponível no software Spring 4.3.2. Este método pode ser descrito como o processo de divisão de uma imagem em segmentos não sobrepostos. O processo divide a imagem em grupos espectrais únicos e inclui um componente espacial. O modelo exige que todos os pixels em um grupo espectral (ou segmento) sejam espacialmente contíguos. Estes segmentos podem ser usados para extrair e classificar feições, produzindo uma imagem melhor classificada. Como resultado, foram identificados os seguintes tipos de uso da terra: Água, Campo, Banhado, Mata Ciliar, Reflorestamento, Área Rural e Área Urbana.

O mapa gerado foi, então, sobreposto, comparado e aglutinado aos mapas de uso da terra propostos pelo Probides e pelo Probio/MMA, os quais serviram como parâmetros na validação das informações geradas na segmentação da imagem.

\section{Critérios para Definição das Bacias de Contribuição}

A delimitação das bacias de contribuição partiu do cruzamento de informações topográficas com as informações de drenagem superficial da bacia hidrográfica da área de contribuição direta da lagoa Mirim. Para tanto, foi gerado o MDE, a partir das curvas de nível (escala de 1:100.000), originando o PI topográfico, o qual incluiu a distribuição espacial dos atributos da superfície do terreno de maneira estruturada e baseada em rede de triângulos irregulares (TIN), onde a superfície é dividida em planos triangulares. Triângulos são formados a partir de nós, cujos valores representativos do atributo do terreno em determinado ponto não são alterados por procedimentos de interpolação que passam a constituir os vértices destes triângulos. É uma estrutura de dados eficiente, onde o tamanho e a forma dos triângulos são variáveis em função da complexidade do terreno, permitindo a fixação de linhas representativas do relevo como lados dos triângulos (Steinke \& Costa, 2002).

Este procedimento foi realizado utilizandose a extensão Watershed basins para ArcView 3.x, na qual foram inseridos os PI's de topografia e drenagem, possibilitando, assim, a delimitação automatizada das bacias de contribuição.

Porém, o procedimento não foi suficiente uma vez que a delimitação automatizada gerou distorções nos limites das bacias de contribuição, quando comparadas às informações das curvas de nível. Por esse motivo, foi necessário realizar procedimentos de edição dos limites, a fim de corrigí-los.

\section{Geração de cargas poluidoras}

Os modelos de simulação de carga poluidora, que representam matematicamente os processos de geração das cargas, têm como objetivo relacionar os diferentes tipos de cobertura do solo e seus impactos na rede de drenagem. Dessa forma, estimativas são realizadas na expectativa de indicar as áreas de maior fornecimento de poluição e as áreas que podem estar ameaçadas ou em desequilíbrio, por serem receptoras destas cargas. Diversos modelos têm sido propostos, os quais procuram, por meio de diferentes cálculos, resolver a questão das cargas poluidoras por diferentes elementos. No presente trabalho, em função da dimensão da área da bacia hidrográfica em estudo, optou-se por estimar a geração de carga poluidora por meio de dois modelos. A escolha de dois modelos distintos visou comparar os resultados gerados na perspectiva de avaliar as vantagens e desvantagens de cada modelo para bacias de grandes dimensões.

Sociedade \& Natureza, Uberlândia, 20 (2): 43-67, DEZ. 2008 
Em primeiro lugar, utilizou-se o modelo para estimativa de poluição difusa disponível no software Basins 4.0 para ArcGis 9, conhecido como Pollutant Loading Application Overview (PLOAD). O PLOAD é um modelo simplificado baseado em sistema de informação geográfica e elaborado para calcular cargas poluidoras em bacias hidrográficas. PLOAD estima fontes não pontuais de poluição por uma média de carga anual, para o poluente especificado. As cargas podem ser calculadas por meio de dois métodos: Método do Coeficiente de Exportação (EC) ou o Método Simples (EMC). A diferença entre os dois métodos reside no fato de que o EC utiliza uma tabela com coeficientes de exportação e não requer dados de precipitação. Já o EMC utiliza precipitação anual para calcular o escoamento superficial. No presente trabalho, utilizou-se o EMC, uma vez que este apresenta os resultados com base nos parâmetros de carga e do escoamento superficial.

No EMC, as cargas poluidoras para cada tipo de poluente específico são calculadas por meio de duas equações. Em primeiro lugar, o coeficiente de escoamento superficial para cada tipo de uso da terra é derivado com a seguinte equação:

$R_{V U}=0.05+\left(0.009 * I_{U}\right)$

Onde:

Tabela 1: Parâmetros (default) de carga PLOAD por tipo de uso

\begin{tabular}{c|c|c|c}
\hline Tipo de uso & N Total $(\mathbf{m g} / \mathbf{l})$ & P Total $(\mathbf{m g} / \mathbf{l})$ & Ss Total $(\mathbf{m g} / \mathbf{l})$ \\
\hline Urbano & 2.0 & 0.5 & 50 \\
\hline Agricultura & 1.0 & 0.2 & 100 \\
\hline Campo & 1.0 & 0.2 & 1.0 \\
\hline Campo/Pastagem & 1.0 & 0.2 & 100 \\
\hline Campo/Mata & 1.0 & 0.2 & 70 \\
\hline Mata & 1.0 & 0.2 & 70 \\
\hline Água & 1.0 & 0.2 & 70 \\
\hline Banhado & 1.0 & 0.2 & 70 \\
\hline Bosque Fluvial & 1.0 & 0.2 & 70 \\
\hline Campo Banhado & 1.0 & 0.2 & 70 \\
\hline
\end{tabular}

Elaboração: Valdir Adilson Steinke, a partir de Basins 4.0 (PLOAD).
$\boldsymbol{R}_{V U}=$ Ao coeficiente de escoamento para cada tipo de uso da terra.

$\boldsymbol{I}_{U}=$ Percentual de Impermeabilidade (extraído da tabela de fator de impermeabilidade do terreno).

As cargas poluidoras são calculadas, então, com a seguinte equação:

$$
L_{P}=\sum_{U}\left(P * P_{J} * R_{V U} * C_{U} * A_{U} * 2.72 / 12\right)
$$

Onde:

$\boldsymbol{L}_{\boldsymbol{P}}=$ Carga Poluidora (Lbs/pound)

$\boldsymbol{P}=$ Precipitação anual (polegada)

$\boldsymbol{P}_{J}=$ Razão de chuva produtora de escoamento (default $=0.9$ )

$\boldsymbol{R}_{V U}=$ Ao coeficiente de escoamento para cada tipo de uso da terra (polegada)

$\boldsymbol{C}_{\boldsymbol{U}}=$ Média de concentração de poluente para cada tipo de uso (mg/l)

$\boldsymbol{A}_{U}=$ Área para cada tipo de uso da terra (acres)

Os valores de precipitação são inseridos pelo usuário no módulo PLOAD. As taxas de carga são derivadas das tabelas de EMC, enquanto as áreas de uso da terra são interpretadas a partir da base de dados da bacia, incluindo os PI's com os limites das bacias e as classes de uso da terra. Os valores utilizados como parâmetros são apresentados na tabela 1 . 
Como segunda alternativa para estimar as cargas de poluição difusa na bacia hidrográfica, utilizou-se o módulo de carga poluidora difusa que foi utilizado no Plano de Desenvolvimento e Proteção Ambiental da Bacia do Guarapiranga (SMA, 2003), o Modelo de Correlação entre Uso do Solo e a Qualidade da Água - MQUAL. Esse modelo é constituído de três módulos inter-relacionados: geração de cargas, simulação dos principais tributários e simulação do reservatório, cada um deles representando os fenômenos de geração e autodepuração das cargas poluidoras em três ambientes considerados: a superfícies do terreno, onde estão as fontes de cargas poluidoras; os rios principais e seus afluentes; e, por fim, o reservatório.

As cargas poluidoras foram estimadas com base no coeficiente de exportação de cada parâmetro de qualidade da água. As estimativas estão associadas ao uso e ocupação da terra. A equação básica do módulo de geração de cargas difusas está descrita a seguir:
$\mathrm{C}_{\mathrm{i}}=\Sigma\left(\mathrm{A}_{\mathrm{i}} \times \mathrm{c}_{\mathrm{i}}\right)$

Onde:

$\mathbf{C}_{\mathbf{i}}$...carga média de cada parâmetro de qualidade de água para cada bacia de contribuição (kg/dia);

$\mathbf{A}_{\mathbf{i}} \ldots$ área ocupada pelas diferentes categorias de uso da terra nas bacias de contribuição $\left(\mathrm{Km}^{2}\right)$;

$\mathbf{c}_{\mathbf{i}}$... coeficientes de exportação de cargas difusas de cada parâmetro ambiental para as diferentes categorias de uso e ocupação da terra $\left(\mathrm{kg} / \mathrm{Km}^{2} / \mathrm{dia}\right)$;

O Módulo de carga é a representação matemática dos processos de geração de cargas poluidoras na bacia hidrográfica destinado a correlacionar a qualidade da água nos principais corpos de água da bacia com o uso e com a intensidade de ocupação da terra. As estimativas foram realizadas para as cargas de Fósforo total (P), Nitrogênio total (N) e Sólidos suspensos (Ss) provenientes de fontes difusas nas bacias de contribuição. As cargas poluidoras foram calculadas em termos de médias anuais e estimadas para cada parâmetro em $\mathrm{kg} / \mathrm{dia}$ (Tabela 2).

Tabela 2: Parâmetros de carga MQUAL por tipo de uso.

\begin{tabular}{ccccc}
\hline Tipo de cobertura & Unidade & N Total & P Total & Ss Total \\
\hline Urbano & $\mathrm{Kg} / \mathrm{km}^{2} / \mathrm{dia}$ & 1,274 & 0,034 & 50 \\
\hline Agricultura & $\mathrm{Kg} / \mathrm{km}^{2} / \mathrm{dia}$ & 2,950 & 0,346 & 230 \\
\hline Campo & $\mathrm{Kg} / \mathrm{km}^{2} / \mathrm{dia}$ & 0,500 & 0,028 & 30 \\
\hline Campo/Pastagem & $\mathrm{Kg} / \mathrm{km}^{2} / \mathrm{dia}$ & 0,500 & 0,028 & 30 \\
\hline Campo/Mata & $\mathrm{Kg} / \mathrm{km}^{2} / \mathrm{dia}$ & 0,600 & 0,039 & 20 \\
\hline Mata & $\mathrm{Kg} / \mathrm{km}^{2} / \mathrm{dia}$ & 0,600 & 0,039 & 20 \\
\hline Água & $\mathrm{Kg} / \mathrm{km}^{2} / \mathrm{dia}$ & - & -- & - \\
\hline Banhado & $\mathrm{Kg} / \mathrm{km}^{2} / \mathrm{dia}$ & 0,700 & 0,034 & 25 \\
\hline Bosque Fluvial & $\mathrm{Kg} / \mathrm{km}^{2} / \mathrm{dia}$ & 0,550 & 0,034 & 30 \\
\hline Campo Banhado & $\mathrm{Kg} / \mathrm{km}^{2} / \mathrm{dia}$ & 0,500 & 0,028 &
\end{tabular}

Elaboração: Valdir Adilson Steinke, adaptado de SMA (2003).

A partir dos resultados apresentados nos dois mapas de geração de carga poluidora difusa, foi estabelecida uma classificação para cada poluente de maneira individualizada (tabela 3) e, ainda, uma classificação geral com o somatório das áreas para cada modelo (tabela 4). A sobreposição dos mapas gerados pelos dois modelos resultou no mapa com as áreas de maior fornecimento de poluição difusa para a bacia, ou seja, PI de Cargas Poluidoras. 
Tabela 3: Parâmetros para hierarquização das cargas

\begin{tabular}{c|c|c|c|c}
\hline Classe & Nota & Fósforo (P) & Nitrogênio (N) & Sólidos Suspensos (Ss) \\
\hline Muito Baixa & 0 & $0,0-1,5$ & $0,0-10,0$ & $0-500$ \\
\hline Baixa & 2 & $1,6-5,0$ & $10,1-40,0$ & $501-1.000$ \\
\hline Moderada & 4 & $5,1-10,0$ & $40,1-99,0$ & $1.001-5.000$ \\
\hline Alta & 6 & $10,1-20,0$ & $99,1-200,0$ & $5.001-10.000$ \\
\hline Muito Alta & 8 & $20,1-40,0$ & $200,1-500$ & $10.001-20.000$ \\
\hline Ext. Alta & 10 & $>40$ & $>500$ & $>20.000$ \\
\hline
\end{tabular}

Elaboração: Valdir Adilson Steinke.

Tabela 4: Classificação Geral após somatório das Notas.

\begin{tabular}{c|c}
\hline Classe & Nota \\
\hline Muito Baixa & $0-5$ \\
\hline Baixa & $5,1-10$ \\
\hline Moderada & $10,1-15$ \\
\hline Alta & $15,1-20$ \\
\hline Muito Alta & $20,1-25$ \\
\hline Ext. Alta & $25,1-30$ \\
\hline
\end{tabular}

Elaboração: Valdir Adilson Steinke.

Para indicar as áreas úmidas sob risco de poluição, foi gerado o PI de Áreas Úmidas a partir dos mapas de áreas úmidas da FEPAM-RS (2006), para aquelas localizadas em território Brasileiro, e de áreas indicadas pelo Probides (2000), para as que se encontram no Uruguai. O PI de Áreas Úmidas foi sobreposto ao PI de cargas poluidoras com a finalidade de identificar as áreas que estão sob maior impacto das atividades antrópicas e podem estar comprometidas na sua biodiversidade. As áreas úmidas receberam uma nota de acordo com a quantidade de carga gerada nas respectivas bacias de contribuição.

\section{RESULTADOS E DISCUSSÃO}

\section{Cobertura da terra}

A classificação por segmentação do mosaico de imagens do Landsat 5 TM gerou o mapa de cobertura da terra, com dez classes (figura 4). Nesse mapa, cada classe de cobertura recebeu uma denominação em função das informações constantes nos mapas de vegetação do Brasil e do Uruguai e de acordo com o tipo de uso da terra atual. 


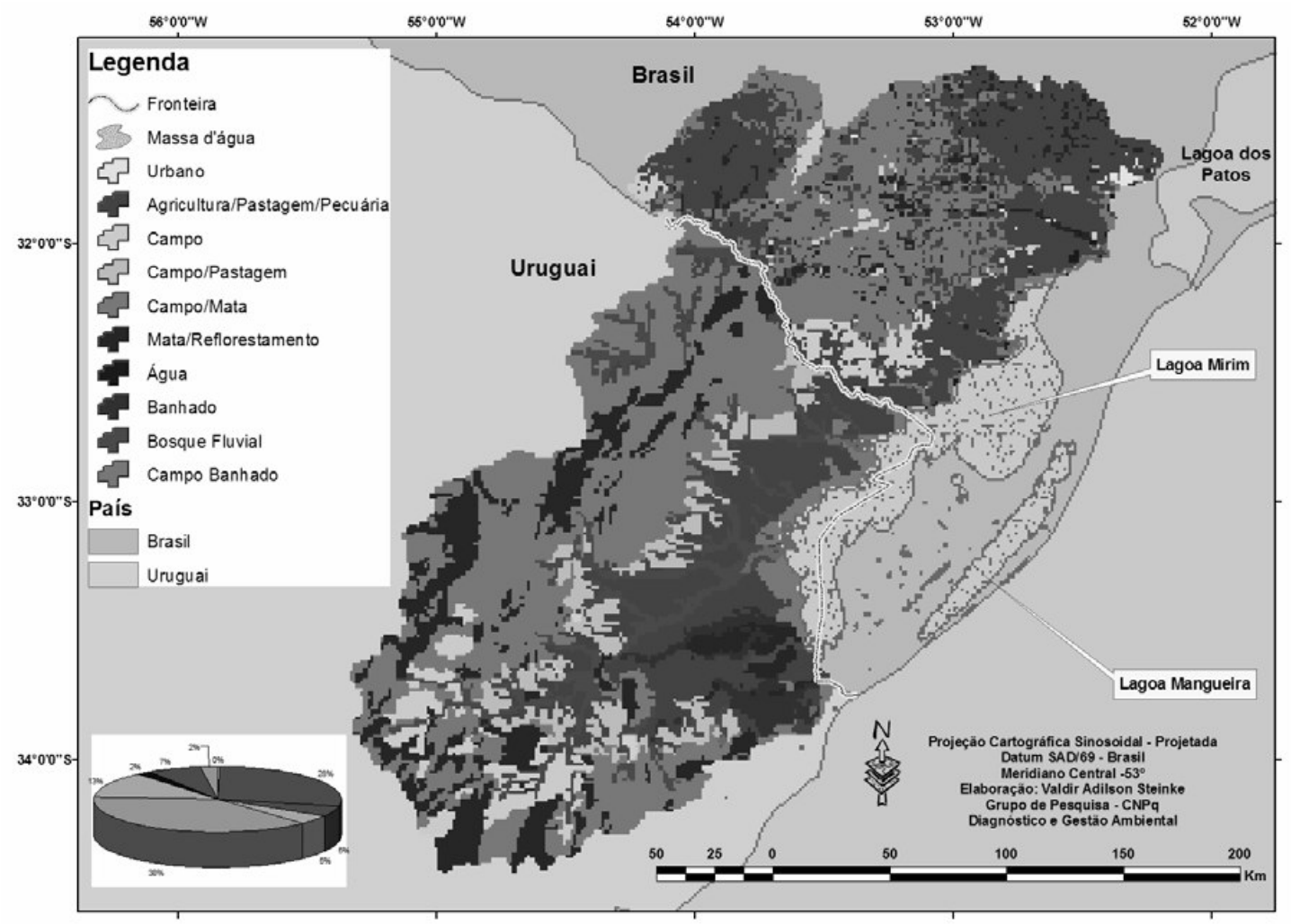

Figura 4: Mapa de cobertura da terra da bacia de Lagoa Mirim.

A cobertura e uso da terra da bacia pode ser caracterizada por dois parâmetros predominantes. O primeiro, com remanescentes de vegetação primária e secundária, é caracterizado pelos campos e suas composições fitofisionômicas, em alguns casos associados com matas/bosques isolados e, também, com a pecuária de corte. O outro parâmetro predominante diz respeito à intensa utilização da região para a agricultura mecanizada, sem remanescentes de vegetação natural.

Estes dois principais representantes de uso da terra na bacia ocorrem, em grande parte, em função dos condicionantes geomorfológicos. As áreas planas e sujeitas à inundações são aproveitadas ao máximo para o cultivo intenso de arroz irrigado. Essas são denominadas regionalmente de "terras baixas", situadas até a cota de $60 \mathrm{~m}$. A região situada nas cotas altimétricas mais elevadas, acima de $60 \mathrm{~m}$, nas quais o relevo se apresenta suave-ondulado, é denominada na região de "terras altas" e é utilizada basicamente para a criação de gado de corte de alto nível competitivo no mercado internacional.

Nas áreas mais elevadas, localizadas principalmente no território brasileiro, foi observada ainda uma nova tendência de ocupação agrícola com plantio de soja, situadas nas proximidades do divisor de águas. Essas áreas, nos últimos anos, estão sendo utilizadas para plantio de soja devido a diferentes motivações, entre as principais estão a busca pela diversificação econômica da região e o receio, por parte dos proprietários de terra, de se tornarem alvo de reforma agrária, uma vez que, historicamente, constitui-se em região de pecuária extensiva de baixa densidade de bovinos por hectare, o que justificaria processos de colonização agrícola.

\section{Sub-bacias de Contribuição}

As bacias de contribuição foram definidas em função de análise integrada, em ambiente SIG, com 
base em parâmetros morfométricos e hierarquia de drenagem até canais de $5^{a}$ ordem, na escala de 1:100.000.

Foi possível individualizar 32 sub-bacias de aporte direto ao corpo hídrico principal, isto é, a Lagoa Mirim (figura 5). Dessas, 22 apresentam, no geral, relevo plano e suave ondulado, com extensas áreas de amplitude altimétrica inferior a 50m, aliadas aos níveis de declividade fraca (até 8,75). As demais, em função de estarem localizadas nas proximidades da lagoa, onde se concentram as regiões mais planas e de fácil acumulo de água durante os períodos chuvosos, caracterizam-se por apresentar menor área de drenagem.

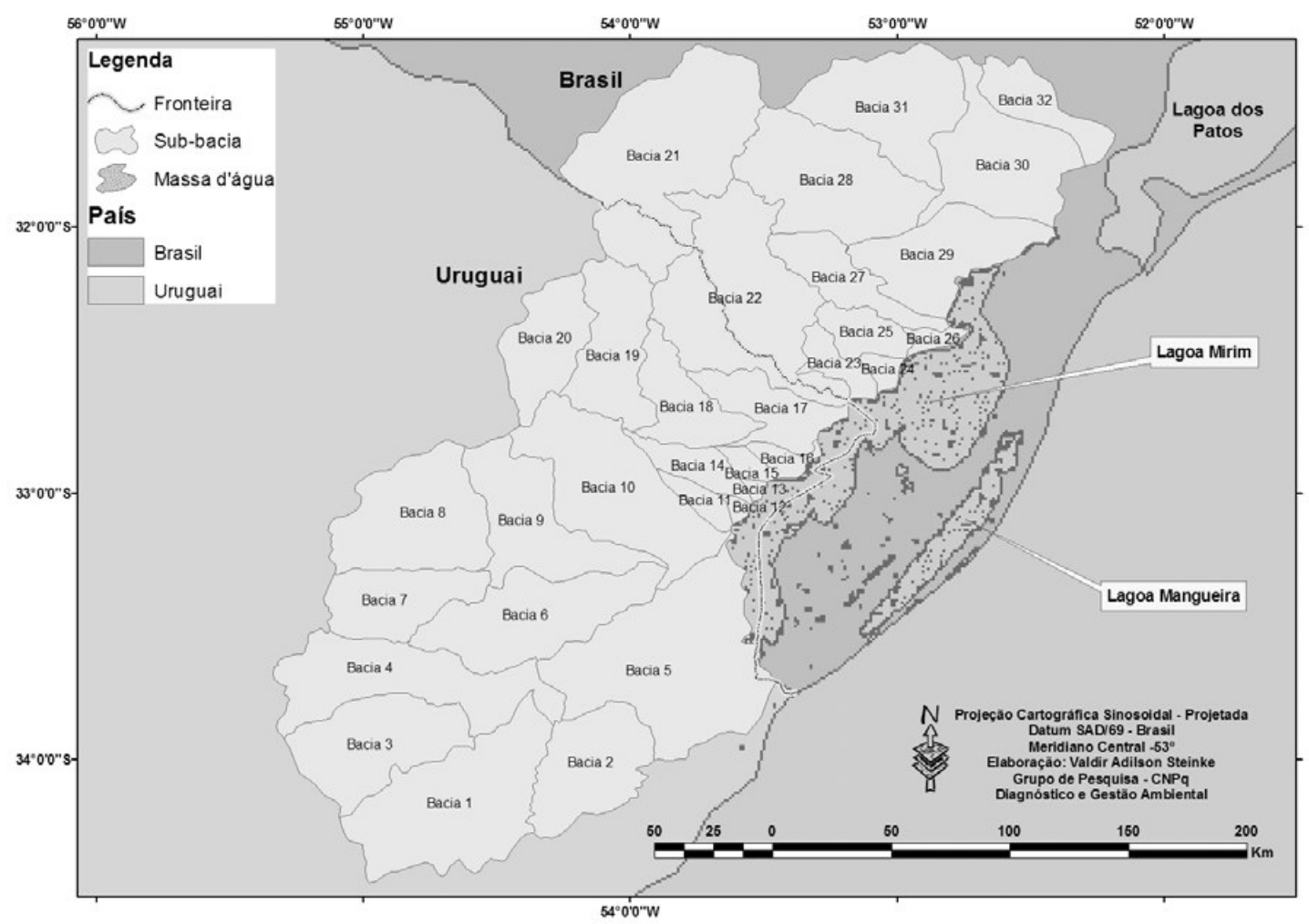

Figura 5: Sub-bacias de contribuição para aporte direto à Lagoa Mirim.

\section{Carga Poluidora estimada pelo Modelo PLOAD}

Os produtos oriundos do modelo PLOAD apresentaram resultados únicos por bacia, sem o detalhamento das áreas internas às sub-bacias. Os dados analisados resultaram do cruzamento entre as bacias de contribuição e o tipo de cobertura da terra para cada sub-bacia. Os parâmetros dos diferentes tipos de uso a que ocorrem foram normalizados e apresentados por um único valor para cada sub-bacia.

A desvantagem que o modelo apresenta constitui-se na utilização de um índice único, representando todas as classes de uso para a bacia. Discretizando-se as áreas internas das sub-bacias analisadas, observou-se, em certa medida, que este coeficiente pode prejudicar uma análise mais refinada do ambiente estudado. O detalhamento da divisão das sub-bacias certamente minimizaria o problema.

Como fator positivo, vale ressaltar a agilidade do processo computacional de geração dos mapas de carga. Basta que seja realizada a divisão das bacias de drenagem e que o mapeamento da cobertura da 
terra esteja adequado ao modelo, isto é, com todas as classes codificadas.

Os processos que antecedem a geração dos mapas são cruciais para a qualidade da informação final. Esses processos necessitam de atenção especial, em função da escala de análise.

Outro aspecto relevante diz respeito às opções de parâmetros. No presente trabalho, foram utilizados três parâmetros, contudo, o modelo disponibiliza, ao usuário, 20 parâmetros, além de uma opção de definição do usuário.

A figura 6 apresenta a carga poluidora estimada por sub-bacia de contribuição para cada poluente mapeado. Os valores encontram-se classificados em uma escala de 0 a 10 , as quais correspondem à nota final de cada bacia.
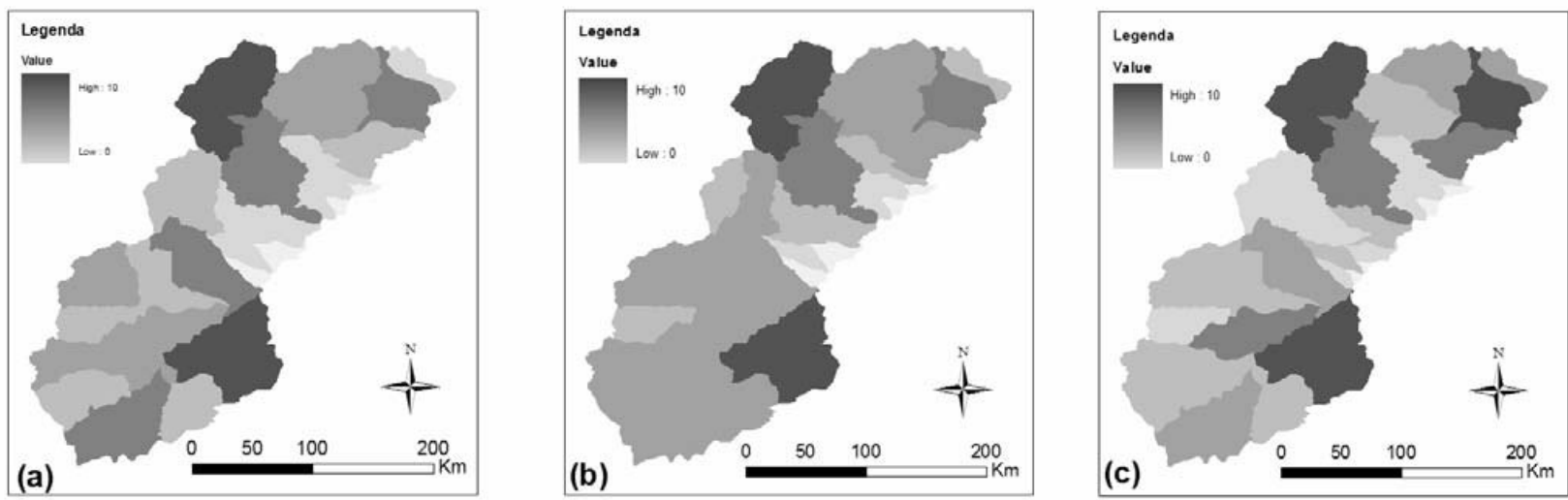

Figura 6: Exportação de carga para Fósforo (a), Nitrogênio (b), Sólidos Suspensos (c).

A distribuição de cargas nas diferentes subbacias apresenta um padrão, o qual reflete os tipos de uso destas bacias, porém, a variável Nitrogênio (b), foi a que apresentou maior homogeneidade entre as sub-bacias. Após a indicação da distribuição dos três poluentes, foi elaborado um mapa final, no qual todos os parâmetros foram somados pelas suas respectivas notas finais com o propósito de indicar as sub-bacias em situação mais crítica com relação à poluição difusa (figura 7). 


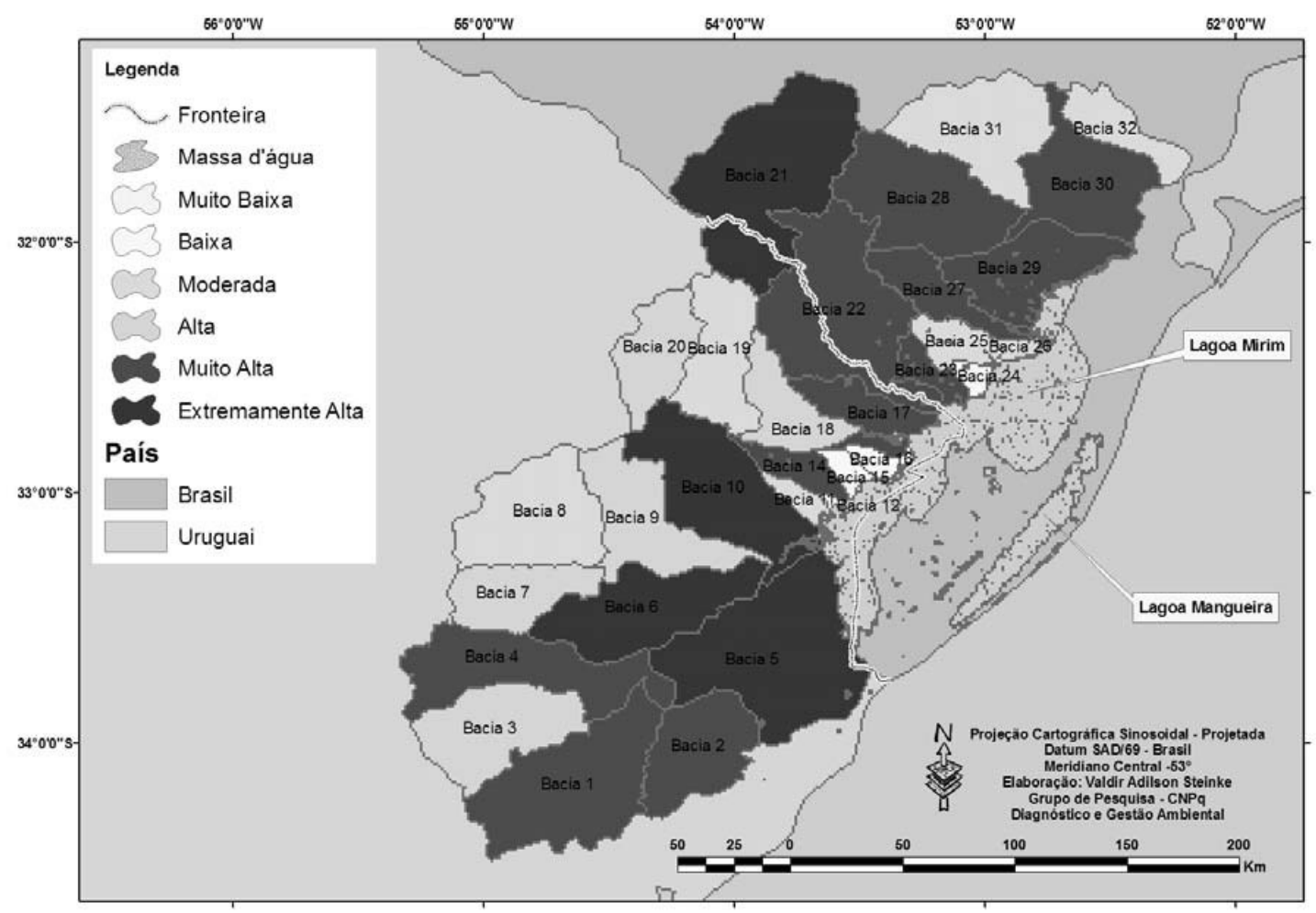

Figura 7: Classificação final das sub-bacias de contribuição (PLOAD).

Como resultado da aplicação do modelo, obtiveram-se 12 sub-bacias enquadradas nas classes de carga poluidora de "alta" a "extremamente alta", oito sub-bacias com carga "moderada", e as demais com carga "baixa" ou "muito baixa". Ressalta-se que as 12 sub-bacias que apresentaram maior carga poluidora ocupam mais de $40 \%$ do território da bacia da lagoa Mirim.

\section{Exportação de Carga por Poluição Difusa - MQUAL}

De acordo com os procedimentos metodológicos propostos, a partir do mapa de cobertura da terra, foram inseridos os parâmetros de carga poluidora ( $\mathrm{P}, \mathrm{N}$ e $\mathrm{Ss}$ ) para cada classe de uso nas sub-bacias de contribuição. Após o processamento dos dados de carga, esses foram classificados em seis grupos, de acordo com uma hierarquia de valores de carga em uma escala de 0 a 10 . Nessa escala, o valor 10 corresponde à maior fonte de poluição difusa para cada parâmetro. A figura 8 apresenta os valores de carga para cada parâmetro de maneira individualizada. 
Exportação de carga poluidora para identificação de áreas úmidas sob risco ambiental na bacia hidrográfica da lagoa mirim Valdir Adilson Steinke, Carlos Hiroo Saito
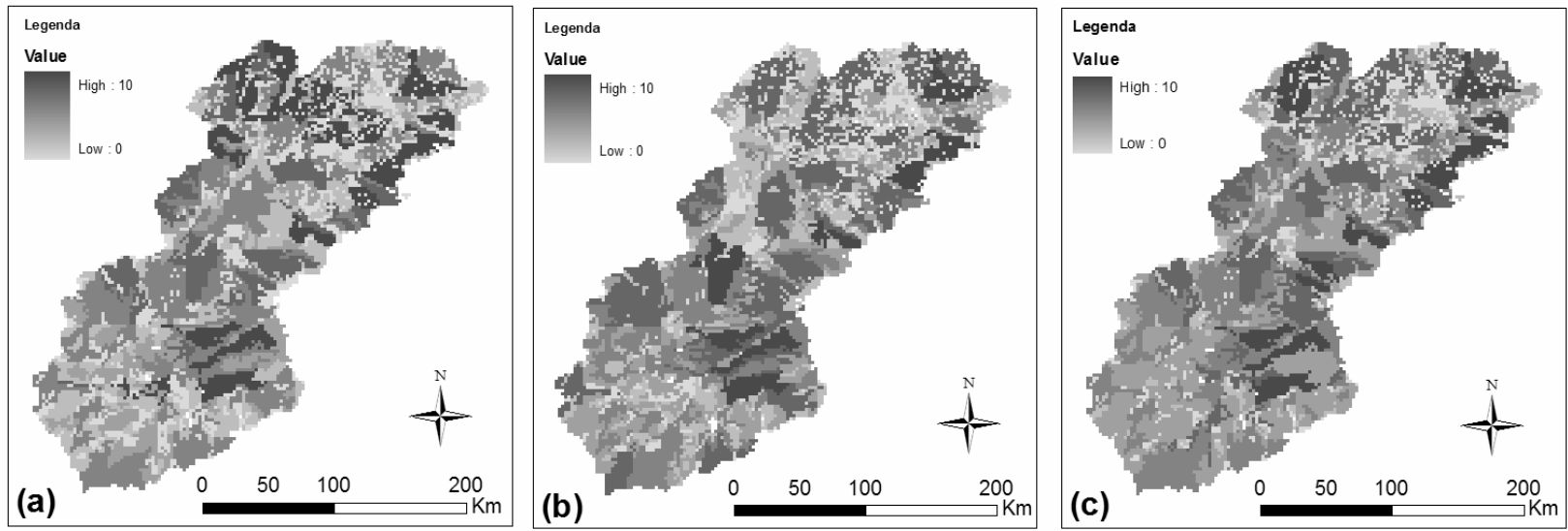

Figura 8: Exportação de carga para Fósforo (a), Nitrogênio (b), Sólidos Suspensos (c).

O somatório dos três parâmetros, conforme indicado na tabela 4, aponta as áreas com maior participação nas cargas da bacia hidrográfica de acordo com a classificação estipulada: Extremamente Alta, Muito Alta, Alta, Moderada, Baixa e Muito Baixa (figura 9).

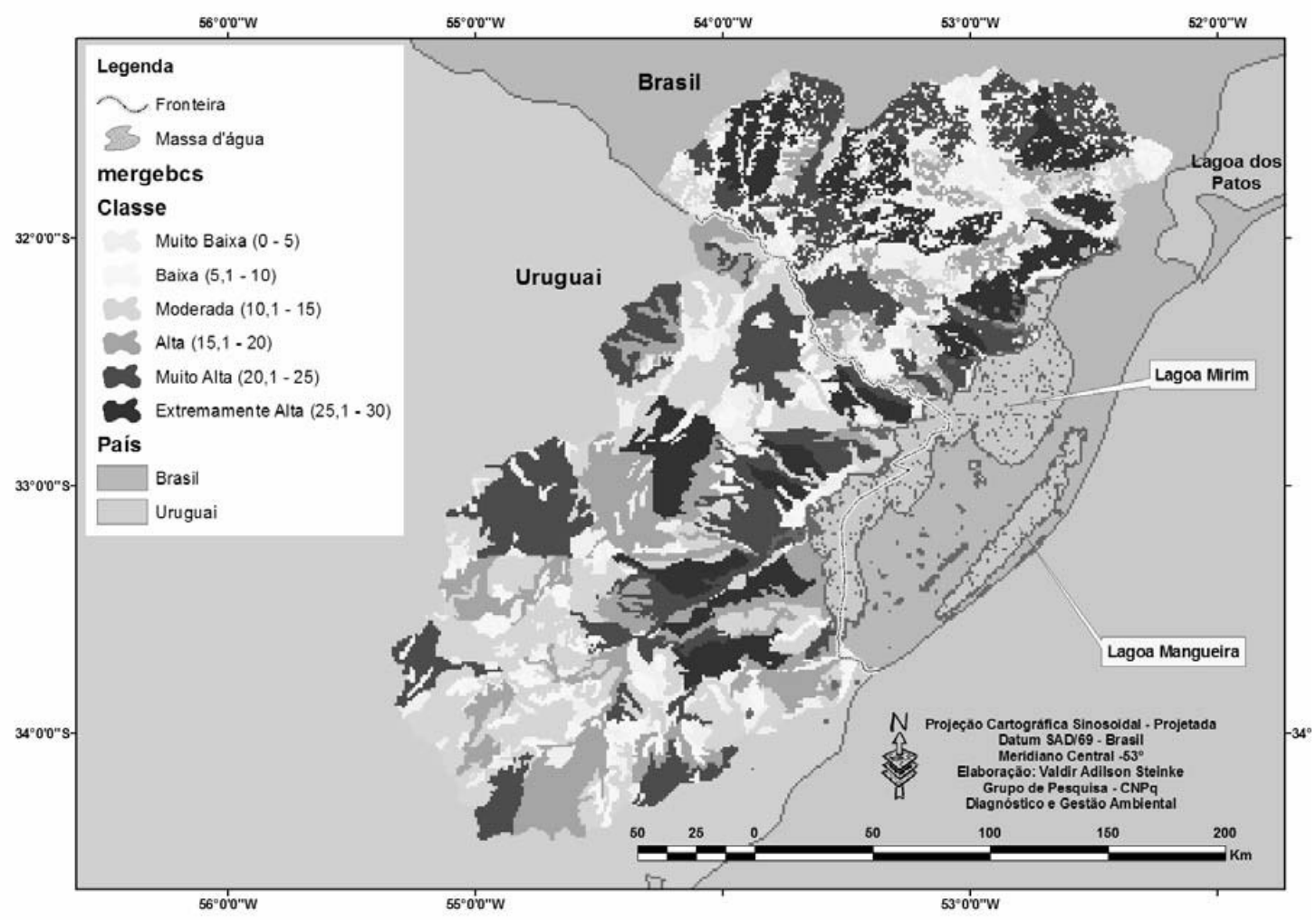

Figura 9: Classificação das áreas de contribuição

Com a utilização do modelo MQUAL, foi possível, então, discretizar as informações de carga internamente para cada bacia de contribuição, pois em função das dimensões da bacia, se faz necessário uma individualização dos parâmetros analisados por subbacia de contribuição. Este procedimento visou classifi- 
car as sub-bacias de acordo com o nível de exportação de carga difusa, de acordo com os critérios estabelecidos nos procedimentos metodológicos. A tabela 5 apresenta um detalhamento das classes de exportação de carga para cada sub-bacia, com a área em $\mathrm{km}^{2}$ correspondente a cada classe na respectiva bacia.

Tabela 5: Classes em $\mathrm{km}^{2}$ por sub-bacia de contribuição.

\begin{tabular}{|c|c|c|c|c|c|c|c|c|}
\hline & \multicolumn{6}{|c|}{ Classes em $\mathrm{Km}^{2}$ por sub-bacia } & \multirow[b]{2}{*}{ Total } & \multirow{2}{*}{$\begin{array}{l}\text { Nota } \\
\text { Bacia }\end{array}$} \\
\hline Bacia & Mto Baixa & Baixa & Moderada & Alta & Mto Alta & Extr Alta & & \\
\hline 1 & 267,2 & 366,1 & 713,9 & $1.068,0$ & 505,9 & & $2.922,1$ & 6 \\
\hline 2 & 274,6 & 127,5 & 420,0 & 290,2 & 464,7 & & $1.578,9$ & 6 \\
\hline 3 & 186,7 & 204,0 & $1.102,6$ & 332,4 & & & $1.828,7$ & 4 \\
\hline 4 & 391,8 & 246,1 & $1.031,8$ & 239,7 & 425,6 & & $2.338,9$ & 6 \\
\hline 5 & 296,4 & 258,7 & 770,9 & $1.218,8$ & 264,1 & 997,6 & $3.811,6$ & 10 \\
\hline 6 & 66,7 & 121,3 & 576,5 & 343,9 & 627,2 & 417,2 & $2.158,7$ & 8 \\
\hline 7 & 98,8 & 130,4 & 442,5 & 593,4 & & & $1.272,0$ & 4 \\
\hline 8 & 308,1 & & 332,5 & & $1.566,1$ & & $2.214,8$ & 4 \\
\hline 9 & 239,8 & 105,9 & 261,9 & $1.223,2$ & & & $1.839,8$ & 6 \\
\hline 10 & 97,8 & 188,9 & 374,8 & 306,1 & 811,0 & 864,1 & $2.652,7$ & 6 \\
\hline 11 & 20,8 & 56,1 & & & & 159,1 & 246,9 & 2 \\
\hline 12 & 5,4 & 34,8 & & & & & 52,1 & $\mathbf{0}$ \\
\hline 13 & 35,8 & & & & & & 48,8 & $\mathbf{0}$ \\
\hline 14 & 77,8 & 38,3 & 84,7 & & 96,3 & 201,9 & 513,1 & 4 \\
\hline 15 & 23,7 & & & & 146,5 & & 185,2 & 2 \\
\hline 16 & & & 90,3 & & 107,7 & & 214,0 & 2 \\
\hline 17 & 79,7 & 164,3 & 308,5 & 75,9 & & 310,0 & $\mathbf{9 5 5 , 3}$ & 4 \\
\hline 18 & 145,4 & 58,4 & 329,6 & & 513,2 & & $1.064,5$ & 4 \\
\hline 19 & 233,7 & 353,0 & 943,0 & & & & $1.548,7$ & 4 \\
\hline 20 & 128,8 & & 195,4 & 277,2 & 597,1 & & $1.218,4$ & 4 \\
\hline 21 & 732,1 & 299,4 & 596,6 & 510,5 & 978,5 & 844,4 & $3.982,4$ & 10 \\
\hline 22 & 634,3 & 387,5 & 577,4 & 290,7 & $1.656,7$ & & $3.568,5$ & 8 \\
\hline 23 & 77,6 & 90,8 & 36,6 & 53,4 & 124,7 & & 406,1 & 4 \\
\hline 24 & 24,1 & & & & 125,9 & & 174,0 & 2 \\
\hline 25 & 65,1 & 71,8 & 168,1 & & & 222,4 & 552,5 & 4 \\
\hline 26 & 4,3 & 24,1 & & & 115,0 & & 169,4 & 2 \\
\hline 27 & 352,7 & 11,3 & 85,1 & 344,9 & 134,0 & & 954,9 & 4 \\
\hline 28 & 829,5 & 220,2 & 161,5 & 211,3 & & $1.087,9$ & $2.538,4$ & 8 \\
\hline 29 & 373,1 & 155,5 & 62,5 & 278,5 & & 795,9 & $1.694,5$ & 8 \\
\hline 30 & 371,7 & 221,0 & 370,7 & 227,1 & & 803,1 & $2.023,6$ & 8 \\
\hline 31 & 881,0 & 287,6 & & & 947,7 & & $2.147,3$ & 6 \\
\hline 32 & 230,2 & 112,8 & & & 464,1 & & 839,0 & 2 \\
\hline Total & $7.554,2$ & $4.335,6$ & $10.037,2$ & $7.885,0$ & $10.671,8$ & $6.703,7$ & $47.715,5$ & 6 \\
\hline
\end{tabular}

Elaboração: Valdir Adilson Steinke. 
No intuito de indicar as sub-bacias mais críticas e ainda servir de parâmetro para uma comparação com o resultado apresentado pelo procedimento de geração de carga do PLOAD, estabeleceu-se, para as sub-bacias, uma nota final, a qual recebeu a mesma padronização de notas e classes utilizadas no trabalho. A figura 10 apresenta a classificação por sub-bacia de contribuição.

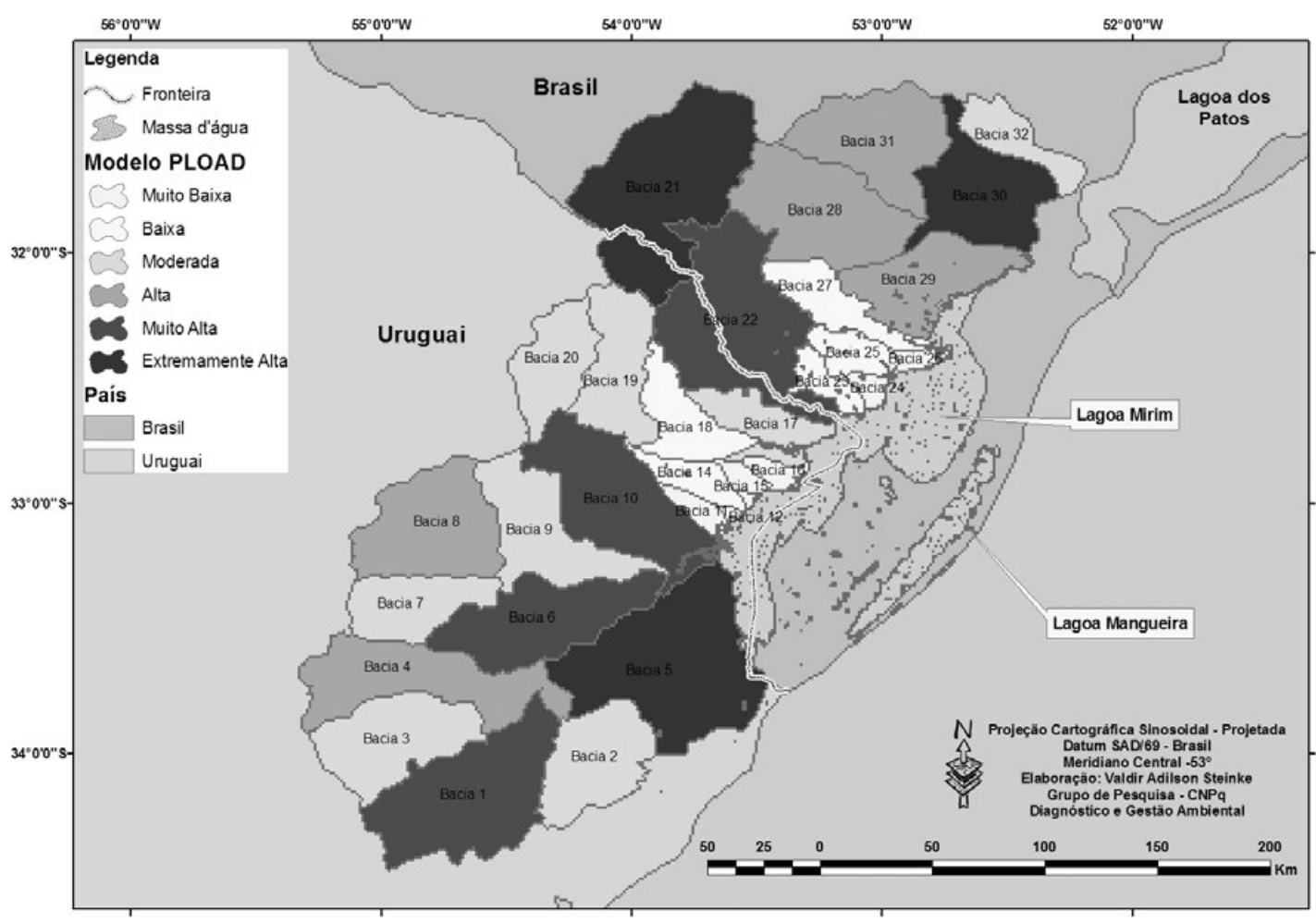

Figura 10: Mapa de classificação das bacias de contribuição (MQUAL).

A tabela 6 apresenta um comparativo entre os resultados finais de ambos os modelos. Foram destacados os resultados de iguais valores e as diferenças para todas as sub-bacias. Dessa forma, das 32 sub-bacias analisadas, 13 apresentaram igual nota final em ambos os modelos. Em 14 sub-bacias, os resultados gerados pelo modelo MQUAL apresentaram valor final de carga superior aos originados pelo modelo PLOAD, enquanto que, em apenas cinco, os valores finais gerados pelo PLOAD foram superiores àqueles gerados pelo MQUAL. 
Tabela 6: Comparativo entre a classificação final das bacias de Contribuição pelos métodos de MQUAL e PLOAD.

\begin{tabular}{|c|c|c|}
\hline Bacia & MQUAL - Nota Bacia & PLOAD - Nota Bacia \\
\hline 1 & 6 & 8 \\
\hline 2 & 6 & 4 \\
\hline 3 & 4 & 4 \\
\hline 4 & 6 & 6 \\
\hline 5 & 10 & 10 \\
\hline 6 & 8 & 8 \\
\hline 7 & 4 & 4 \\
\hline 8 & 4 & 6 \\
\hline 9 & 6 & 4 \\
\hline 10 & 6 & 8 \\
\hline 11 & 2 & $\mathbf{0}$ \\
\hline 12 & $\mathbf{0}$ & $\mathbf{0}$ \\
\hline 13 & $\mathbf{0}$ & $\mathbf{0}$ \\
\hline 14 & 4 & 2 \\
\hline 15 & 2 & $\mathbf{0}$ \\
\hline 16 & 2 & $\mathbf{0}$ \\
\hline 17 & 4 & 4 \\
\hline 18 & 4 & 2 \\
\hline 19 & 4 & 4 \\
\hline 20 & 4 & 4 \\
\hline 21 & 10 & 10 \\
\hline 22 & 8 & 8 \\
\hline 23 & 4 & 2 \\
\hline 24 & 2 & $\mathbf{0}$ \\
\hline 25 & 4 & 2 \\
\hline 26 & 2 & $\mathbf{0}$ \\
\hline 27 & 4 & 2 \\
\hline 28 & 8 & 6 \\
\hline 29 & 8 & 6 \\
\hline 30 & 8 & 10 \\
\hline 31 & 6 & 6 \\
\hline 32 & 2 & 4 \\
\hline & \multicolumn{2}{|c|}{ Resultados iguais } \\
\hline & \multicolumn{2}{|c|}{ Carga Maior por meio do MQUAL } \\
\hline & \multicolumn{2}{|c|}{ Carga Maior por meio do PLOAD } \\
\hline
\end{tabular}

Comparando-se os resultados gerados por meio dos dois modelos, observa-se que, em todas as sub-bacias, a diferença nos valores finais não ultrapassou uma (1) classe e, independentemente do modelo, as diferenças apresentadas mostraram um padrão entre os valores de ambos os modelos. Isto indica que, quando a análise for realizada exclusivamente por índice de bacia de contribuição, é possível utilizar qualquer um dos modelos sem grandes prejuízos ao resultado final.

Porém, se o objetivo da investigação for o detalhamento interno das sub-bacias, o modelo MQUAL apresenta-se como melhor opção de escolha, 
pois, além do índice geral da sub-bacia, existe a possibilidade de identificar em que segmento da bacia estão localizadas as maiores fontes de poluição difusa com seus devidos parâmetros.

Os procedimentos para geração do modelo MQUAL são mais complexos e trabalhosos, pois, além de processamentos automatizados, demandam mais tempo para a edição dos dados tabulares. Sendo assim, recomenda-se a utilização do modelo PLOAD em trabalhos que requerem resultados mais generalistas e rápidos como, por exemplo, estudos prévios para licenças ambientais de viabilidade locacional, enquanto que o modelo MQUAL é indicado para um momento posterior da análise, na perspectiva de detalhamento das informações. Obviamente, em ambos os casos, o usuário não pode perder de vista a necessidade de atenção com os aspectos pertinentes à escala de análise.

No presente trabalho, optou-se pelos resultados gerados pelo modelo MQUAL, pois a necessidade de detalhar os fatos internos a cada subbacia visou apresentar as áreas úmidas sob ameaça de poluição e, ainda, indicar as áreas que representam as maiores fontes de poluição difusa para cada área úmida analisada.

\section{Áreas úmidas sob Ameaça de Poluição}

As áreas úmidas caracterizam-se por uma geomorfologia extremamente plana, com declividade mínima, o que faz com que o nível da lâmina d'água permaneça abaixo da superfície durante a maioria dos meses do ano. São constituídas por águas represadas em terra firme, de escassa profundidade, com terrenos saturados de água e caracterizados, principalmente, como pântanos com vegetação aquática e herbácea.

A identificação de áreas úmidas consideradas ameaçadas por poluição partiu da sobreposição do plano de informação de carga poluidora por sub-bacia de contribuição com os planos de informação das áreas úmidas da bacia como um todo (incluindo Brasil e Uruguai, foram contabilizadas 60 áreas úmidas que representam $2.787 \mathrm{~km}^{2}$ da bacia).

É importante salientar que essas áreas correspondem a áreas que se encontram alagadas durante todo o ano e suas respectivas áreas de abrangência estão relacionadas ao período de menor volume de água.

As áreas úmidas ameaçadas por poluição foram indicadas em função da carga de poluição difusa apresentada para as suas respectivas bacias de contribuição. Assim, foi possível estabelecer uma classificação da fragilidade das áreas úmidas (tabela 7) diante do tipo de cobertura da terra encontrado nas sub-bacias.

Tabela 7: Classificação final das áreas úmidas da Lagoa Mirim.

\begin{tabular}{|c|c|c|}
\hline CLASSE & No. de Áreas & $\mathbf{K m}^{2}$ \\
\hline Muito Baixa & 12 & 147,7 \\
\hline Baixa & 2 & 64,8 \\
\hline Moderada & 10 & 527,8 \\
\hline Alta & 16 & 542,7 \\
\hline Muito Alta & 17 & $1.353,5$ \\
\hline Extremamente Alta & 3 & 151,4 \\
\hline $\begin{array}{ll}\text { Total } \\
\end{array}$ & 60 & $2.787,8$ \\
\hline
\end{tabular}

Elaboração: Valdir Adilson Steinke 
Conforme mostra a figura 11, a concentração das áreas mais ameaçadas por poluição ocorre na faixa costeira ao oeste da Lagoa Mirim, compreendida em até $50 \mathrm{~km}$ da margem da Lagoa. A faixa mais ampla está situada em território Uruguaio. No Brasil, esta faixa é mais estreita e atinge não mais que $30 \mathrm{~km}$, considerando-se a mesma margem. Ao norte, pelas margens do canal de São Gonçalo, uma planície de banhados se forma desde a extremidade da lagoa Mirim até atingir a Laguna dos Patos com uma extensão de aproximadamente $50 \mathrm{~km}$ em linha reta.

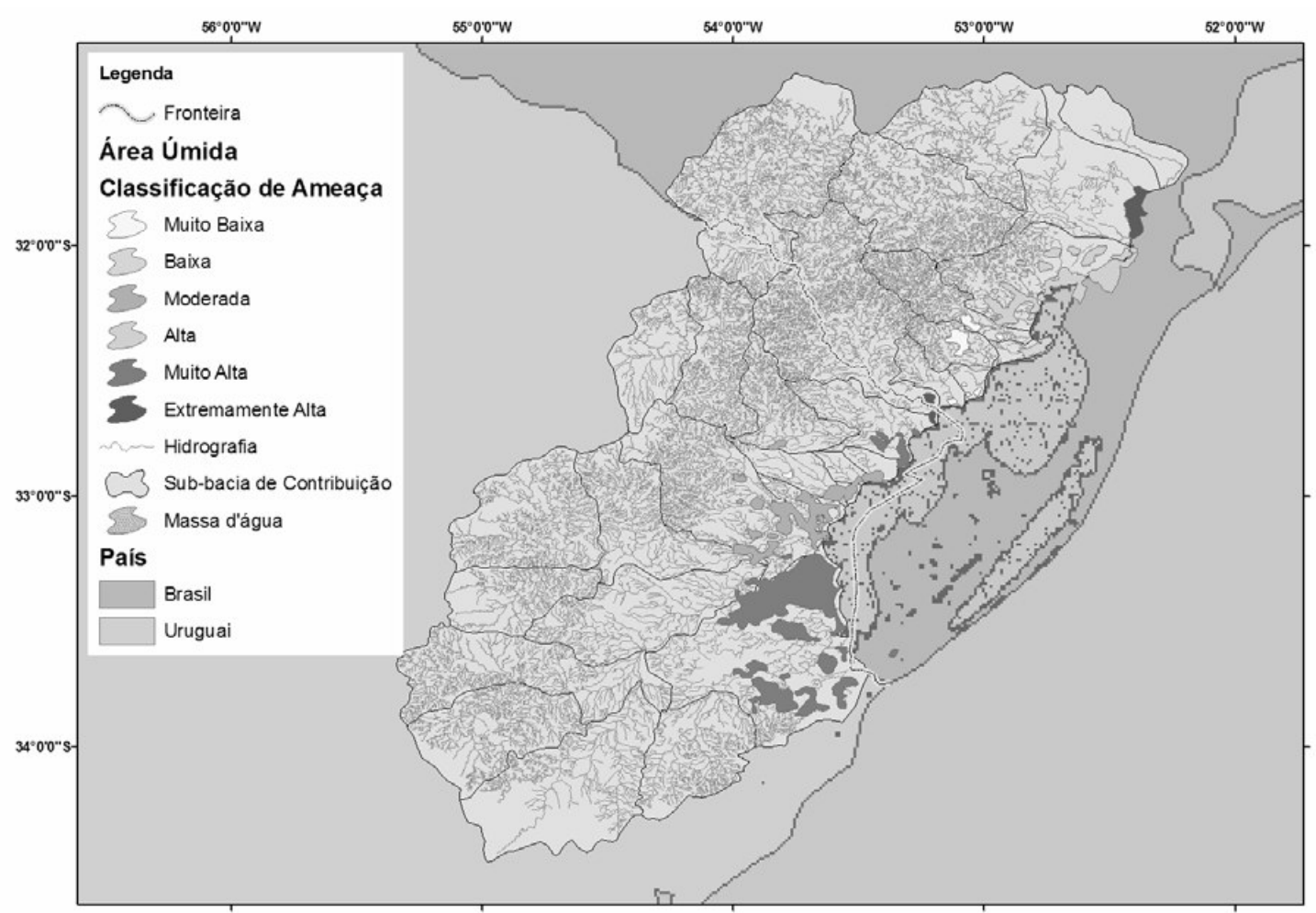

Figura 11: Distribuição espacial das áreas úmidas classificadas devido ao grau de recebimento de carga poluidora.

Além da indicação das áreas úmidas ameaçadas, em função de toda a complexidade de usos de suas respectivas bacias de contribuição, a sobreposição dos PI's revelou outros aspectos conflitantes e que merecem atenção das comunidades diretamente envolvidas e dos gestores dos países que compartilham o recurso. Pode-se citar como exemplo, o fato de algumas áreas ameaçadas estarem sendo ocupadas por atividade de produção de arroz irrigado por inundação. Considerando-se que os banhados são importantes áreas para a conservação da biodiversidade, parece inadequado que estejam sendo utilizados para algum tipo de atividade econômica, ao invés de estarem sendo preservados.
Durante as visitas à área de estudo, observouse que os banhados que ainda "resistem" são aqueles nos quais os investimentos em processos de drenagem seriam muito elevados, o que inviabilizaria a produção, pois esses estão mais suscetíveis às grandes inundações dos períodos chuvosos.

Esses aspectos tornam os banhados ainda mais vulneráveis, pois estão pressionados em seu entorno imediato pelas áreas de plantio de arroz que avançam ao máximo na direção das áreas úmidas, e suas conexões são viabilizadas ainda pela dinâmica hidrológica do principal corpo d'água, a Lagoa Mirim. Ressalta-se que os banhados uruguaios possuem uma margem de proteção que, em alguns casos, chega a 
até $10 \mathrm{~km}$, como é o caso da região da foz do rio Cebollati.

\section{CONSIDERAÇÕES FINAIS}

A proposta apresentada teve como objetivo identificar as áreas úmidas da Lagoa Mirim sob risco de poluição, entretanto, o cenário que motivou esta discussão passa por questões mais amplas, entre elas, a articulação de informações geoambientais em nível de bacia hidrográfica transfronteiriça como subsídio à gestão compartilhada destas áreas.

A aglutinação dessas informações merece atenção imediata dos gestores públicos dos governos brasileiro e uruguaio em esfera federal. Não se pode aceitar que, em um momento histórico de disponibilização de informações georreferenciadas, países que compartilham bacias hidrográficas estejam "engessados" em procedimentos protocolares em nível de representações diplomáticas. $\mathrm{Na}$ atualidade, torna-se urgente a criação de um núcleo técnico binacional capaz de subsidiar as discussões no nível da geopolítica.

Exatamente pela falta de articulação técnica entre os dois países envolvidos, a busca e a aglutinação de informações e dados a respeito da Lagoa Mirim constituíram um dos maiores desafios da pesquisa. No Brasil, diferentes instituições públicas têm gerado dados georreferenciados, contudo, ainda são tímidas as propostas que procuram criar bancos de dados a nível nacional. Ressaltam-se aqui as iniciativas do IBGE, MMA, ANA, ANEEL, CPRM entre outros, mas estas ainda carecem de articulação interinstitucional e principalmente de divulgação. No Uruguai, este aspecto não é diferente, embora exista uma base consistente de informações articulada pelo PROBIDES.

Outro aspecto que merece destaque reside na discussão dos conflitos socioambientais regionais existentes. A realidade brasileira é muito semelhante à uruguaia, os conflitos envolvem questões de desenvolvimento econômico induzidas pela "vocação" da região, a qual, conforme indicaram os dados, reduz-se, simplesmente, ao binômio arroz-gado de corte.

Compatibilizar esse modelo econômico limitado com a sustentabilidade dos ecossistemas envolvidos significa, também, a manutenção do próprio meio de produção, uma vez que os banhados funcionam como parâmetros de comportamento antrópico na região, pois refletem como está sendo conduzido o sistema na sua totalidade.

Para o caso da Lagoa Mirim, esta é uma discussão que deve ser encaminhada de maneira imediata para a Comissão Mista da Lagoa Mirim, representada por três membros de cada país envolvido. Sugere-se que a discussão sobre a conservação dessa região sirva como experiência para as outras áreas úmidas nacionais e aquelas compartilhadas com outros países.

A informação principal gerada pelo presente trabalho, isto é, o volume de carga poluidora de aporte direto ao sistema hídrico da Lagoa Mirim possui caráter relevante, uma vez que a contextualização das informações, integradas a nível binacional, representa um avanço significativo no entendimento da bacia como unidade sócioambiental de análise, na qual os impactos das ações antrópicas possam ser mensurados, espacializados e, em última análise, serem utilizadas como subsídio em procedimentos de gestão compartilhada.

\section{REFERENCIAS BIBLIOGRÁFICAS}

ARANOFF, S. Geographic Information Systems: A Management Perspective. Ottawa: WDL Publications, 1995.

ASSAD, E.D.; SANO, E.E. Sistemas de Informações Geográficas - Aplicações na Agricultura. Brasília: EMBRAPA, 1998 (2ª edição).

BURROUGH, P.A. Principles of Geographical Information Systems for Land Resources Assessment. New York: Oxford University Press, 1986. 
BURROUGH, P. A.; MCDONNELL, R.A. Principles of geographical information systems. New York: Oxford University Press, 1998.

CALIJURI, M. L. \& RÖHM, S. A. 1995. Sistemas de Informações Geográficas. Viçosa: UFV. 1995. 34p.

CAMARA, G. \& MEDEIROS, J.S. GIS para Meio Ambiente. São José dos Campos: INPE, 1998.

CÂMARA, G. Desenvolvimento de Sistemas de Informação Geográfica no Brasil: Desafios e Oportunidades (Palestra proferida na Semana de Geoprocessamento do Rio de Janeiro, Outubro de 1996).

CARPENTER, S. R.; CARACO, N. F.; CORRELL, D. L.; HOWARTH, R. W.; SHARPLEY, A. N.; SMITH, V. H. Nonpoint pollution of surface waters with phosphorus and nitrogen. Ecological Applications, Washington, v.8, n.3, p. 559-568, 1998.

DAVIS, C. A.. Geoprocessamento: Dez Anos de Transformações. In: TOMAMASELLI, A. M. G.; ROSSET, C. F.; DAVIS, C. A.; YUAÇA F.; FONSECA, F.; COLOMINA, I.; SANTOS, M.; RODRIGUES, P.; FIGOLI, S. Geoinformação: Passado, Presente e Futuro. Curitiba: EspaçoGEO, 2001

GBUREK, W. J.; SHARPLEY, A. N. Hydrologic controls on phosphorus loss from upland agricultural watersheds. Journal of Environmental Quality, Madison, v.2, n.27, p. 267-277, 1998.

GENELETTI, D. An approach based on spatial multicriteria analysis to map the nature conservation value of agricultural land. Journal of Environmental Management. 2006

GIUPPONI, C., EISELT, B., GHETti, P. F. A. Multicriterial approach for mapping risks of agricultural pollution for water resources: The Venice Lagoon watershed case study. Journal of Environmental Management, v. 56, p. 259-269, 1999.
GOLIN, T. A Fronteira: Governos e Movimentos Espontâneos na Fixação dos Limites do Brasil com o Uruguai e a Argentina. Porto Alegre: L\&PM, 2002.

KOTZIAN, H. B.; MARQUES, D. M. Lagoa Mirim e a convenção Ramsar: um modelo para ação transfronteiriça na conservação de recursos hídricos. Rega - Revista de Gestão de Água da América Latina, Santiago, v. 1, no 2, 101 - 111, 2004.

KUHNLE, R.A.; BINGER, R.J.; FOSTER, G.R.; GRISSINGER, E.H. Effect of land use on sediment transport. Water Resources. Research, Washington, v. 32, p. 3189-3196, 1996.

LEPISTÖ, A., GRANLUND, K., KORTELAINEN, P., RÄIKE, A. Nitrogen in river basins: Sources in the surface waters and peatlands, and fluxes to estuaries in Finland. Science of the Total Environmental, v. 365, n. 1-3, 238-259, 2006.

LOPES, F., MERTEN, G. H., FRANZEN, M. et al. Utilização de P-Index em uma bacia hidrográfica através de técnicas de geoprocessamento. Revista Brasileira de Engenhatia Agrícola e Ambiental, Campina Grande, v. 11, n. 3, p. 312-317, 2007.

MACHADO, R. E.; VETTORAZZI, C. A. Simulação da produção de sedimentos para a microbacia hidrográfica do Ribeirão dos Marins (SP). Revista Brasileira de Ciência do Solo. Viçosa, v. 27, n. 4, p.735-741, Jul/Aug. 2003.

MACHADO, R. E., VETORAZZI, C. A.; XAVIER, A. C. Simulação de cenários alternativos de uso da terra em uma microbacia utilizando técnicas de modelagem e geoprocessamento. Revista Brasileira de Ciência do Solo, Viçosa, v. 27, n. 4, p.727-733, Jul/Aug. 2003.

MACLEOD C.; HAYGARTH, P. A review of the significance of non-point source agricultural phosphorus to surface water. Scope Newsletter, Devon, n. 51, p.1-10, 2003. 
MANSOR, M. T. C., TEIXEIRA FILHO, J.; ROSTON, D. M. Avaliação preliminar das cargas difusas de origem rural, em uma sub-bacia do Rio Jaguari, SP. Revista Brasileira de Engenhatia Agrícola e Ambiental, Campina Grande, v. 10, n. 3, p.715-723, Jul/Set. 2006.

MATEJICEK, L. BENESOVÁ, L.; TONIKA, J. Ecological modeling of nitrate pollution in small river basins by spreadsheets and GIS. Ecological Modelling, n. 170, p. 245-263, 2003.

MINISTÉRIO DO MEIO AMBIENTE. Mapas de Cobertura Vegetal dos Biomas Brasileiros. Disponível em: <http://www.mma.gov.br/ index.php?ido=conteudo.monta\&idEstrutura $=72 \&$ idMenu= 3813 > Acesso em: 01 out. 2007.

MINISTÉRIO DO MEIO AMBIENTE. RAMSAR. Disponível em <http://www.mma.gov.br/ port/sbf/dap/ramsar.html> Acesso em 23 mar. 2007.

MIRANDA, J. I. Fundamentos de Sistemas de Informações Geográficas. Brasília: Embrapa Informação Tecnológica, 2005.

MOHAMMED, H., YOHANNES, F., ZELEKE, G. Validation of agricultural non-point source (AGNPS) pollution model in Kori watershed, South Wollo, Ethiopia. Internacional Journal of Applied Earth Observation and Geoinformation, n. 6, p. 97-109, 2004.

MONTAÑA, J. R. \& BOSSI, J. Geomorfologia de los humedales de la cuenca de la laguna Merín em el departamento de Rocha. Universidade de la Republica. Serie documentos de trabajo ${ }^{\circ} 2$. 32p. 1995.

MUFANO, M., CECCHI, G., BAIOCCO, F., MANCINI, L. River pollution from non-point sources: a new simplified method of assessment. Journal of Environmental Management, n. 77, p. 93-98, 2005.

PALIWAL, R., SHARMA, P., KANSAL, A., Water quality modeling of the river Yamuna (India) using QUAL2E-UNCAS. Journal of Environmental Management, v. 83, n. 2, p. 131-44, 2007.

PROBIDES - Programa de Conservación de la Biodiversidad y Desarrollo Sustentable en los Humedales del Este. Plan Director Reserva de Biosfera Bañados del Este. 2000.

ROCHA, C. H. B, Geoprocessamento: tecnologia transdisciplinar. Juiz de Fora: Ed. Do Autor, 2000.

RODRIGUES, M. Geoprocessamento: um retrato atual. Fator GIS, Curitiba, v. 1, n. 2, p. 20-23, 1993.

SCHOU, J. S., SKOP, E., JENSEN, J. D. Integrated agri-environmental modeling: A cost-effectiveness in the Vejle Fjord watershed, Denamark. Journal of Environmental Management, v. 58, p. 199-212, 2000.

SHIGAKI, F., SHARPLEY, A. \& PROCHNOW, L. I. Animal-based agriculture, phosphorus management and water quality in Brazil: options for the future. Scientia Agricola, Piracicaba, v. 63, n. 2, p. 194-209, Mar./Abr. 2006.

SILVA, A. S.; PORTO, M. F. A. A utilização do modelo WinHSPF no estudo das cargas difusas de poluição da bacia do ribeirão da Estiva, SP. In: SIMPÓSIO BRASILEIRO DE RECURSOS HÍDRICOS, 15, 2003, Curitiba. Anais... Curitiba: ABRH, 2003. 1 CD-Rom.

SIVERTUN, A. PRANGE, L. Non-point source critical area analysis in the Gisselö watershed using GIS. Environmental Modelling \& Software, v. 18, p. 887-898, 2003.

STEINKE, V. A.; COSTA, D. A. de A. Determinação de Feições Geomorfológicas a partir da Técnica de Multiplicação de Bandas Espectrais e do Modelo Numérico do Terreno. In: SIMPÓSIO NACIONAL DE GEOMORFOLOGIA, 4, 2002, São Luis. Anais... São Luis: Universidade Federal do Maranhão, 2002, 1 CD-Rom

Sociedade \& Natureza, Uberlândia, 20 (2): 43-67, DEZ. 2008 
TANIK, A.; BELER BAYKAL, B.; GONENC, I. E. The impact of agricultural pollutants in six drinking water reservoirs. Water Science and Technology, v. 40, n. 2, p. 11-17, 1999.

VIGHI, M.; CHIAUDANI, G. Eutrophication in Europe: the role of agricultural activities. In: HODGSON, E. (ed.). Reviews in environmental toxicology 3. Amsterdam: Elsevier, p. 213-258, 1987.

WITT, M.; BEHRENDT, H. Nitrogen and phosphorus emissions from soil to surface water in the Rhine and Elbe basins. Water Science and Technology, v. 39, n. 12, p. 109-116, 1999.

XAVIER-DA-SILVA, J. Geoprocessamento e SGI's. Curso de Especialização em Geoprocessamento. Rio de Janeiro: LAGEOP/ UFRJ, 1999, 1 CR-Rom.

XAVIER-DA-SILVA, J., CARVALHO FILHO, L. M. Sistemas de Informação Geográfica: Uma Proposta Metodológica. In: CONFERÊNCIA LATINOAMERICANA SOBRE SISTEMAS DE INFORMAÇÃO GEOGRÁFICA, 4. SIMPÓSIO BRASILEIRO DE GEOPROCESSAMENTO, 2., 1993, São Paulo. Anais... São Paulo: USP, 1993. p. 609-628.

XIAO, H., JI, W. Relating landscape characteristics to non-point source pollution in mine waste-located watersheds using geospatial techniques. Journal of Environmental Management, v. 82, n. 1, p. 111119, 2007.

YUAN, D., LIN, B., FALCONER, R. A., TAO, J. Development of an integrated model for assessing the impact of difuse an point source pollution on coastal waters. Environmental Modelling \& Software, v. 22, n. 6, 871-879, 2007. 